\title{
Orthognathic Surgery for Mandible
}

\author{
Varghese Mani
}

\subsection{Introduction}

Proper balance and harmony between the different parts of the face-forehead, eyebrows, eyes, nose, ears, cheeks, lips, mouth, jaws, chin, etc.-are the main factors deciding aesthetics. Aesthetic evaluation is mandatory to understand the problems systematically. During the primate evolution, jaws lost many functions, and the size suffered a gradual reduction, which resulted in an orthomorphic face. The facial muscles gained fine expression and smile, the exceptional features of Homo sapiens.

Mandible forms the movable lower part of the head. Mandible is attached to the upper part of the head by ligaments and musculature. It articulates with the glenoid fossa of temporal bone through temporomandibular joint, a synovial joint having translator and rotator movements (ginglymoarthrodial). These movements facilitate chewing and grinding functions. In our prehuman ancestors, the body of the mandible was parallel. In humans, since the brain case has expanded, the temporal bones were pushed apart, TMJ followed suit giving the lower jaw a parabolic contour. The Simian shelf reduced to genial tubercles to facilitate speech and to compensate and strengthen the jaw and the chin developed in humans. Metaphorically it is often stated that "the brain case has expanded at the expense of the jaws".

In some people, surgical repositioning of the mandible may be required to achieve an ideal facial form and restore functions such as mastication and breathing.

Electronic Supplementary Material The online version of this chapter (https://doi.org/10.1007/978-981-15-1346-6_68) contains supplementary material, which is available to authorized users.

V. Mani $(\bowtie)$

Department of Oral and Maxillofacial Surgery, Mar Baselios

Dental College, Kothamangalam, Kerala, India

\subsection{Surgical Anatomy of the Mandible} (Fig. 68.1a, b)

Mandible is the sturdiest bone of the face with strong basal bone and the alveolar part housing the dentition. The near round protuberances seen bilaterally at the cephalic end of the mandible are called condyles, and they form its articulation with the TMJ. The mandibular condyles articulate with the temporal bone and help in the rotatory and translatory movements of the mandible as well as to transmit forces from the mandible to the skull base. A good understanding of the gross anatomy of the mandible is essential to understand its surgical implications. This needs to include the TMJ, the dentition, the supporting ligaments, and the muscles of mastication (Fig. 68.2a, b) and facial expression.

On the medial aspect of the vertical ramus is the mandibular foramen just posterior to halfway between the anterio-posterior width of the vertical ramus almost in line with the most concave part of the anterior border of the ramus. Just above is the lingula, a triangular prominence to which the sphenomandibular ligament is attached. Mandibular neurovascular bundle enters the mandibular foramen on the lingual side of the mandible and runs below the tooth roots in the body of the jaw, in the inferior alveolar canal. It curves upward and backward by about $2 \mathrm{~mm}$ and gives out the main branch, mental nerve, below the second premolar area, and gives sensory supply to the lower lip and chin [1]. 

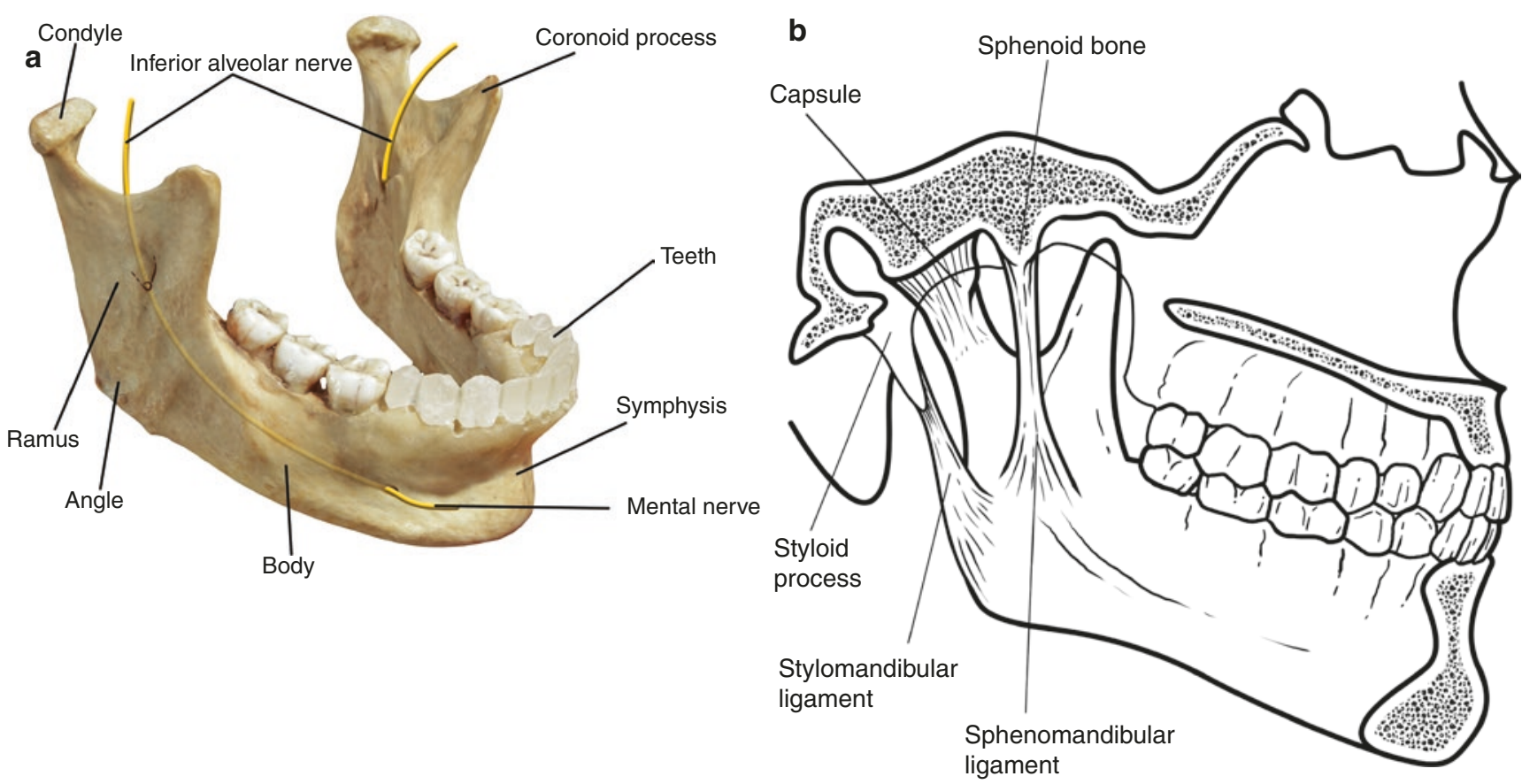

CAssociation of Oral and Maxillofacial Surgeons of India

Fig.68.1 (a) Gross anatomy of mandible, (b) ligaments attached to mandible
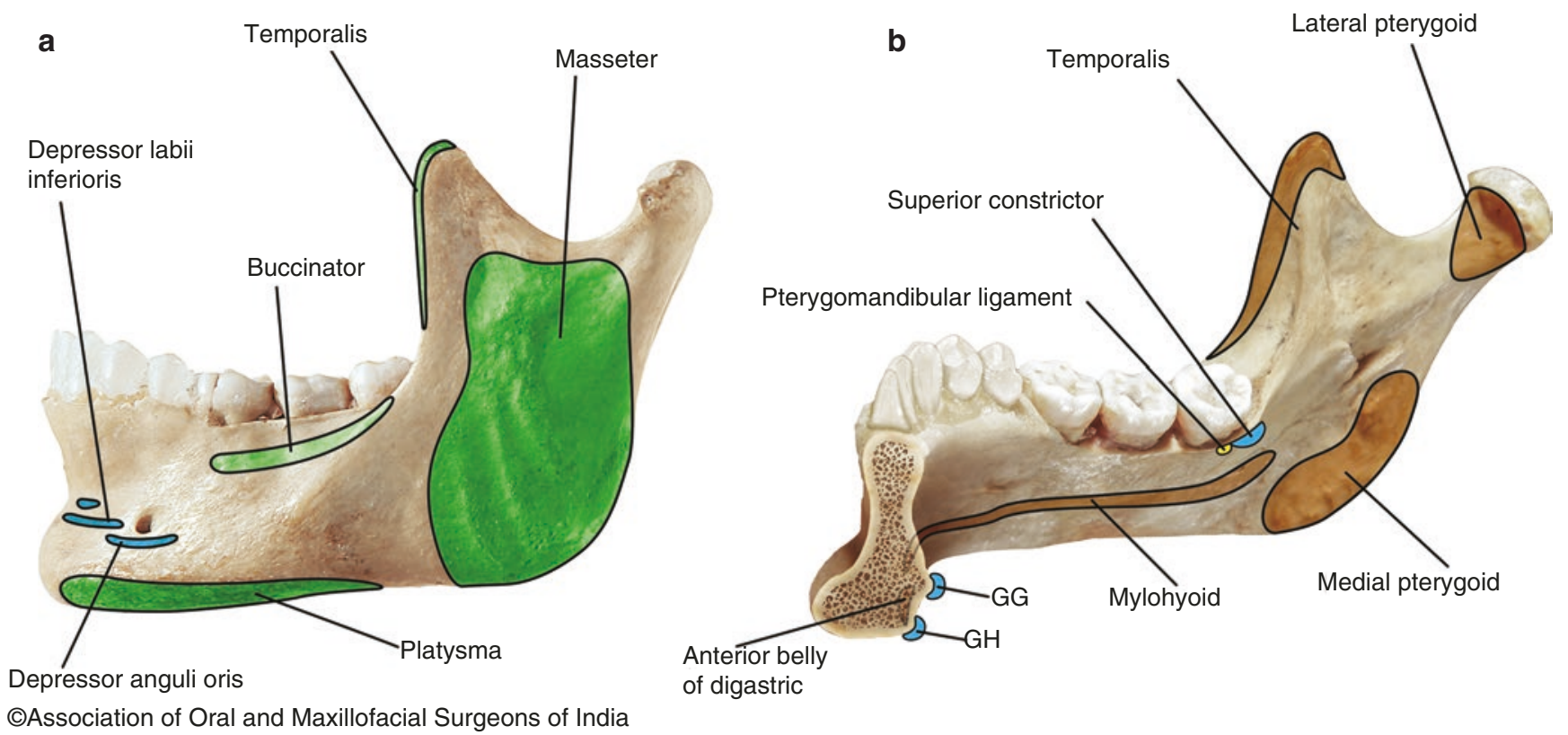

Fig. 68.2 Muscles attached to mandible. (a) Buccal aspect and (b) lingual aspect. (GG) Genioglossus and (GH) Geniohyoid 


\subsection{Classification of Deformities of the Mandible (Table 68.1)}

Table 68.1 Classification of dentofacial deformities

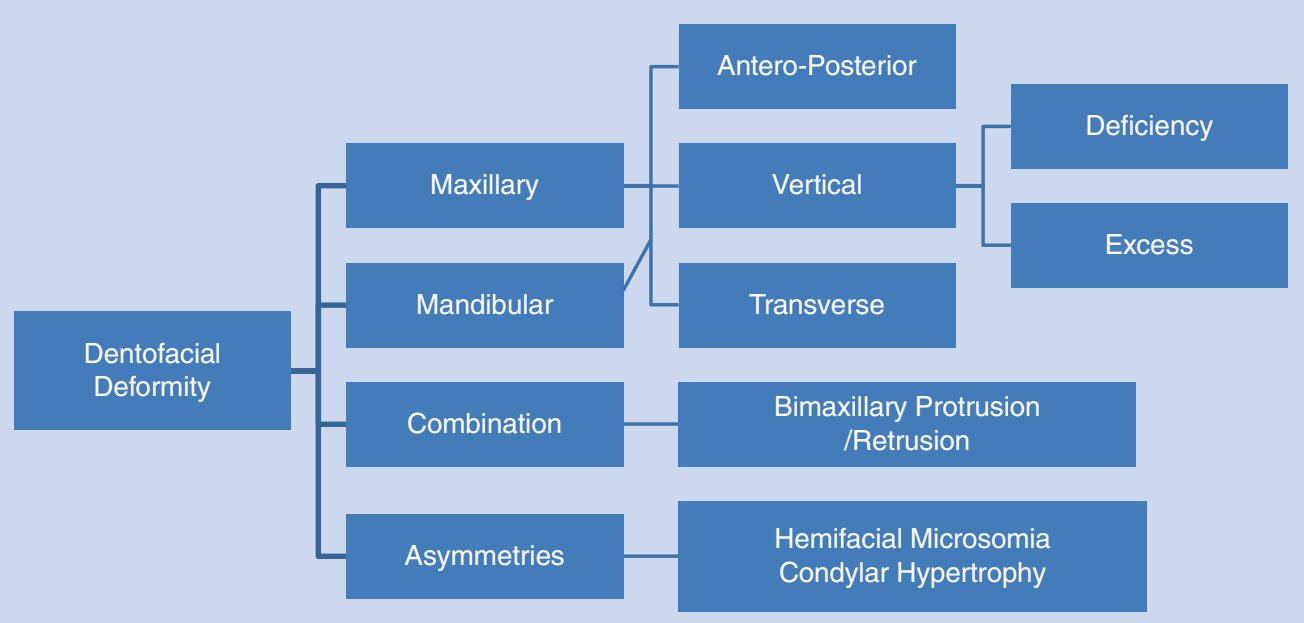

Deformities of the jaws can be associated with the dento-alveolar complex, the skeletal base or both.

They may be either an excess or a deficiency.

These problems can occur in three different vectors: Antero-posterior, Transverse and Vertical
Before venturing into the classification of the jaw deformities it will be appropriate to assess the relationship of the lower jaw to the rest of the face. Certain parameters are used to assess the deformity objectively. Clinical evaluation is the most important of them all. Face has to be assessed frontally and laterally.

Profile analysis of the face is the most important of them all-it could be convex, straight, or concave. Convexity can be due to protruded maxilla or retruded mandible/chin. Concave face can be due to retruded maxilla or prognathic mandible/chin (Fig. 68.3a, b, c). a

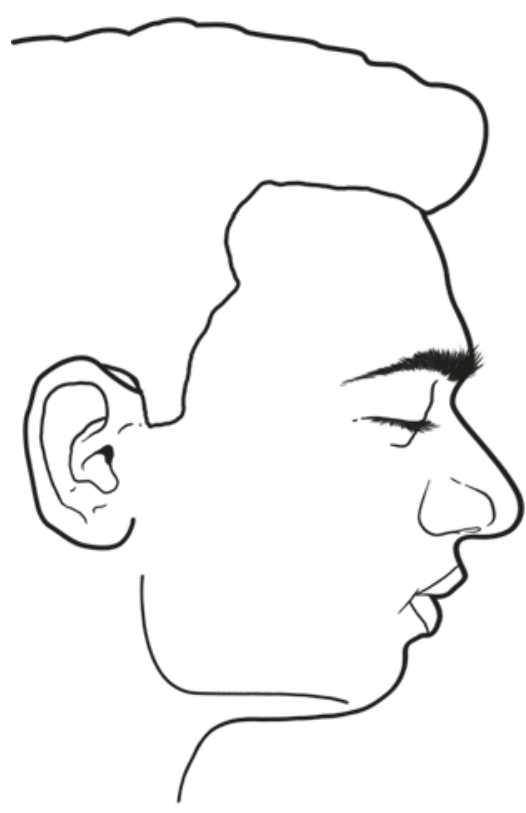

b

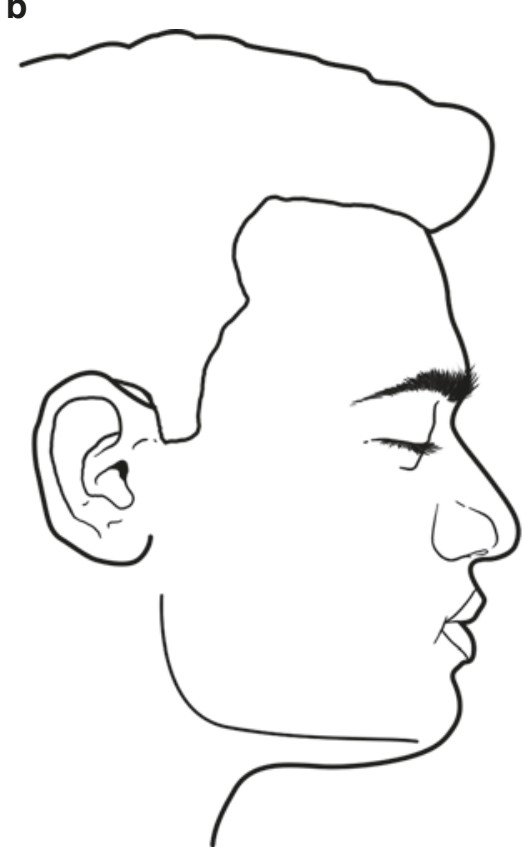

C

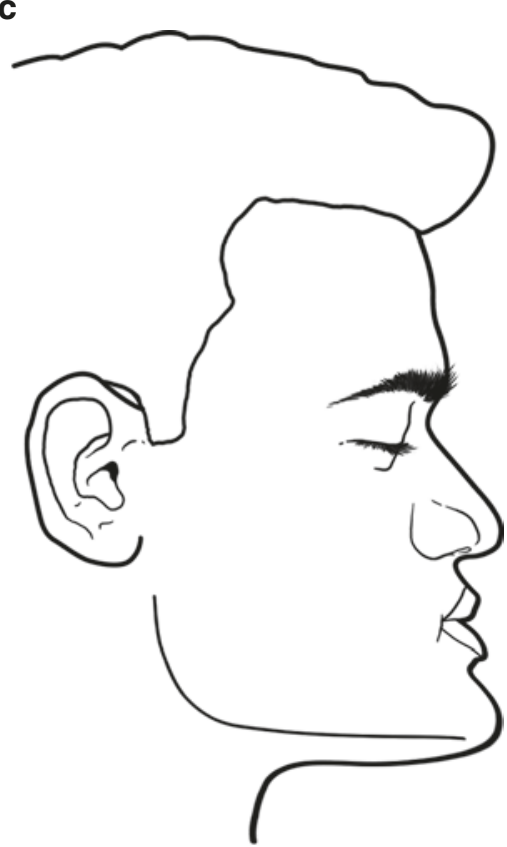

CAssociation of Oral and Maxillofacial Surgeons of India

Fig. 68.3 On profile analysis face can be convex (a), straight (b), or concave (c) 


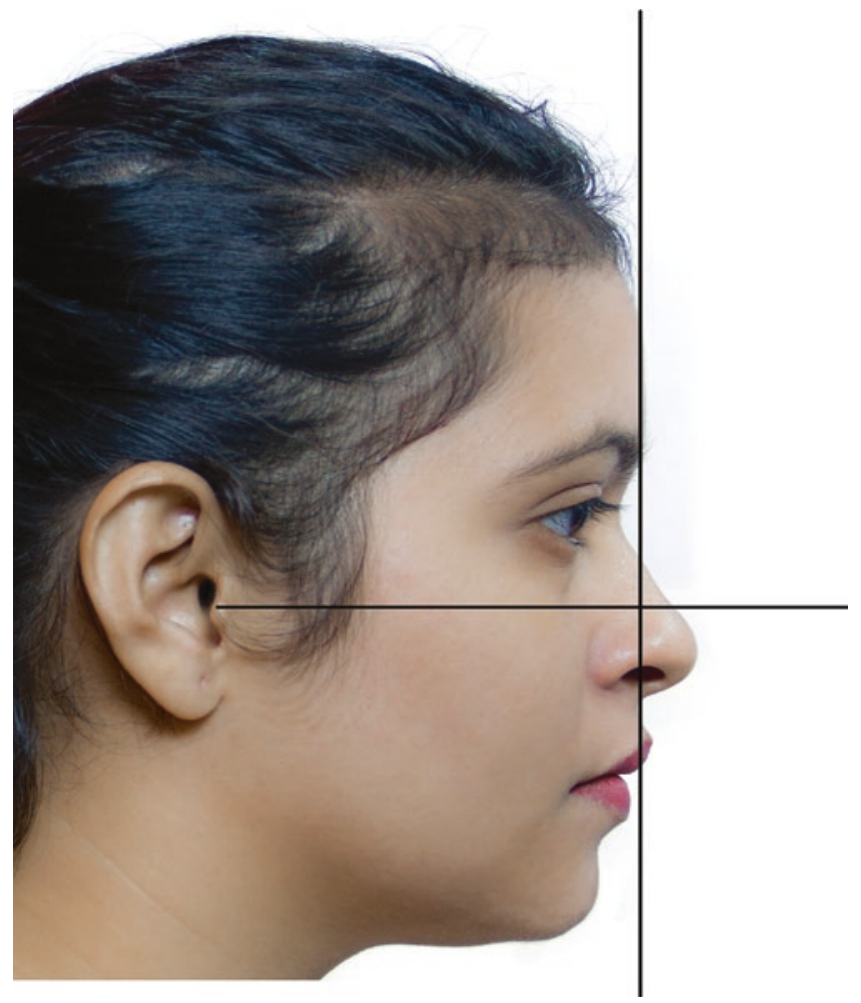

CAssociation of Oral and Maxillofacial Surgeons of India

Fig. 68.4 Subnasale perpendicular to FH plane

Subnasale perpendicular is another important tool for assessing the profile. A line is drawn perpendicular to the Frankfort horizontal plane through the point Subnasale. This line is expected to go through the upper vermilion border, $2 \mathrm{~mm}$ anterior to the lower vermilion border and $4 \mathrm{~mm}$ anterior to the soft tissue (Fig. 68.4) Pogonion. $+/-2 \mathrm{~mm}$ is considered to be within normal limits. This is an important assessment tool for understanding the sagittal relationship of both the maxilla, mandible and dentition.

Likewise another perpendicular line is drawn from Nasion. (N. Perpendicular). This line is ahead by $5.3 \pm 6.7 \mathrm{~mm}$ in males and $6.9 \pm 4.3 \mathrm{~mm}$ in females. This indicates the position of mandible. Regarding the bony pogonion this line is ahead by $4.3 \pm 8.5 \mathrm{~mm}$ in males and $6.5 \pm 5.1 \mathrm{~mm}$ in females. This indicates the position of the chin. Angle SNB is $80 \pm 2$ normally. Less indicates retruded mandible and more indicates protrusion of mandible. All these measurements are in relation to the cranial base, the portion that is not changed in routine orthognathic surgery. (Fig. 68.5) (Refer Chap. 66 for further details).

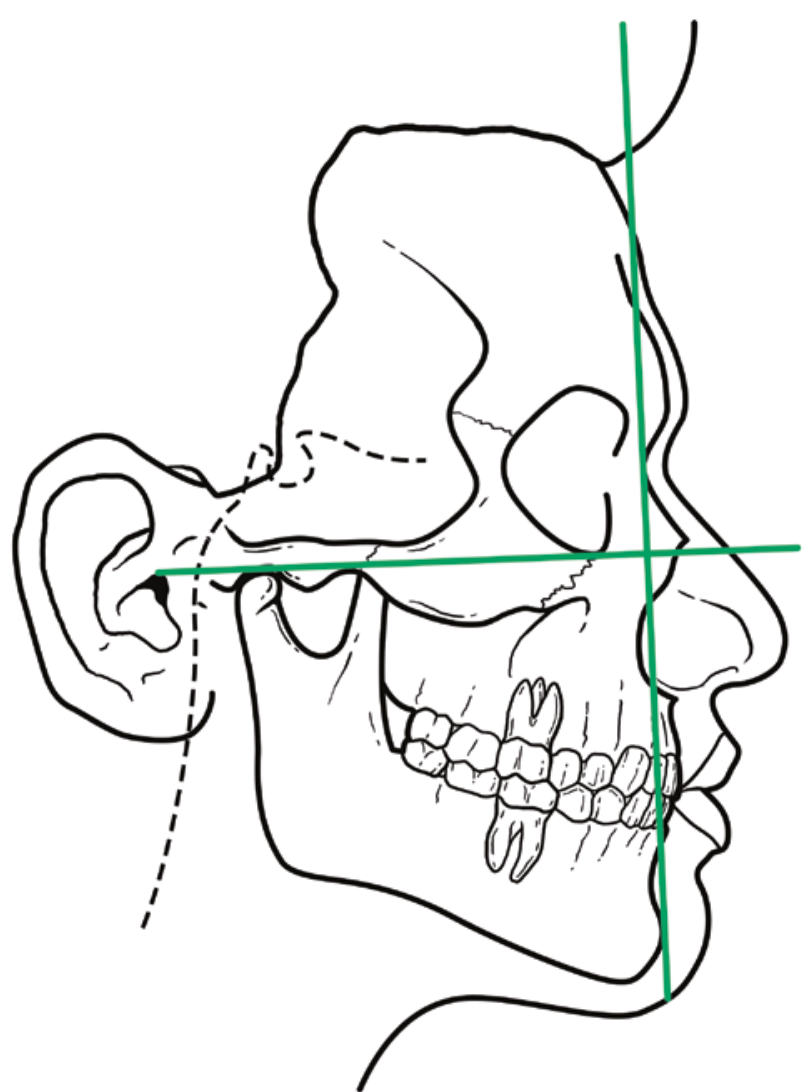

CAssociation of Oral and Maxillofacial Surgeons of India

Fig. 68.5 Nasion perpendicular to FH plane

- Mandibular prognathism
(a) Skeletal
(b) Dento- alveolar

- Mandibular retrusion
(a) Skeletal
(b) Dento- alveolar

- Mandibular Transverse Deformity
(a) Broad
(b) Narrow

- Chin Deformity-Excess
(a) Vertical
(b) Transverse
(c) Antero posterior

- Chin deformity deficient
(a) Vertical
(b) Transverse
(c) Antero posterior

- Deep bite deformity

- Open bite deformity(Apertognathia)

- Asymmetry 
Specific conditions like presence of deep bites and open bites can occur with these clinical situations and may help us understand the dentoalveolar compensations that occur with them. Assessment of patients is done with facial analysis and cephalometrics.

\subsubsection{Mandibular Excess}

Common cause for mandibular excess is either developmental or genetic. Very large mandible may be associated with acromegaly.

The clinical features associated with mandibular excess are the following:

1. Prognathic mandible.

2. Anterior cross bite.

3. Elongated face.

4. Relatively long lower third of the face

5. Stomion-menton length-proportionately long.

6. Concave facial profile.

7. Lower lip and chin are more anteriorly placed than normal (SN perpendicular)

8. Class III relationship of occlusion.

9. Angle SNB-more than $82^{\circ}$.

\subsubsection{Mandibular Deficiency}

It is often due to genetical or developmental reasons. Ankylosis of temporomandibular joint, trauma to mandibular condyle and aplasia of condyle can also cause deficiency in mandibular growth.

Clinical features associated with mandibular deficiency are the following:

1. Bird face appearance.

2. Severe over jet.

3. Class II relationship of dentition.

4. Crowding of lower anterior teeth.

5. Flaring compensation of lower anterior teeth.

6. Face appears small.

7. Lower third of the face is short.

8. Stomion-menton is proportionately short.

9. Labiomental fold is usually absent.

10. Chin neck angle is obtuse.

11. Angle SNB-less than $78^{\circ}$.

12. Angle FHP N P-less than $82^{\circ}$.

\subsubsection{Deformities of Chin}

Deformities of chin could be three dimensional-vertical, anterio-posterior, or horizontal.

Vertical and anterio-posterior excess of chin are usually associated with mandibular prognathism. Though in prognathic mandible, chin appears prominent, it need not be so in objective analysis. Hence it is essential that the chin be assessed independently in relation to the other structures. To assess the vertical discrepancy, the best technique is to measure the length from stomion of the lower lip to the menton and compare this to the length obtained from measuring the subnasale to stomion of the upper lip, in rest position. The former should be double the latter normally.

\subsubsection{Facial Asymmetry}

The reasons for facial asymmetry are many.

A few of the etiological factors are the following:

1. Hemifacial microsomia/dysplasia

2. Unilateral cleft lip and palate, and other unilateral clefting syndromes

3. Childhood trauma especially to the condyle

4. Discrepancy in blood supply to the maxillofacial region

5. Habits

6. Early unilateral loss of teeth

7. Faulty use of functional appliances

8. Pathologies and childhood surgeries of the face

Asymmetry could be pan facial or limited to certain areas. Frontal analysis is the ideal method to assess asymmetries. Drawing vertical and horizontal parallel lines on the face will help to locate the area of asymmetry. This can also be done using a grid. PA cephalogram and frontal photographs are helpful in analyzing facial symmetry.

Orthognathic surgery to the mandible involves numerous procedures that facilitate the correction of deformities of the mandible and its dentoalveolar complex in all planes of space. This encompasses a wide array of techniques which may be classified based on the anatomical location they are applicable to.

Osteotomies of the Mandible

1. Dentoalveolar complex
(a) Anterior subapical
(b) Total subapical

2. Midline symphyseal osteotomy

3. Body osteotomy

4. Ramus Osteotomy

(a) Vertical sub-sigmoid osteotomy-intra- and extraoral

(b) Sagittal split ramus osteotomy (BSSO)

5. Subcondylar osteotomy 
The discussion of all the techniques is beyond the scope of this chapter, and hence, detailed description of the vertical ramus osteotomy, the sagittal split ramus osteotomy, and theÚnterior subapical osteotomy are provided here.

\subsection{Ramus Osteotomies}

Movement of the mandible in the antero-posterior direction is usually achieved by ramus osteotomy. Limberg in 1925 reported subcondylar oblique osteotomy [2]. Thomas, Robinson, Shira, and others described buccal osteotomy which involved the ramus. Later, Caldwell and Letterman (1954) described vertical subcondylar osteotomy by extraoral approach, which became very popular [3]. This technique minimized trauma of the inferior alveolar neurovascular bundle.

In 1927 Wassmund described the inverted "L" osteotomy. Though the primary indication was mandibular prognathism, many surgeons advocated vertical osteotomy and certain modifications like inverted "L" osteotomy [4] and "C" osteotomy for advancement of the mandible [5]. Bone grafting has to be done to fill the gap created (Fig. 68.6).

In 1937 Lane described a sagittal osteotomy. Obwegeser modified the Lane's technique in 1955, and the technique of sagittal split osteotomy is credited to him. Sagittal split is a versatile technique and has the following superiority over others [6]. It gives great flexibility in repositioning the distal tooth-bearing segment. There is better cancellous bone contact, which enhances healing. The alterations in the position of the condyles and muscles of mastication are minimal. There is no extraoral scar. Injury to the marginal mandibular nerve is avoided. However, chance of injury to the inferior alveolar neurovascular bundle is high [7].

Dal Pont made the modification to sagittal split by a vertical cut through the lateral cortex [8]. Hunsuck extended the medial cut only to a point above the lingula. This minimized trauma to overlying tissue [9].

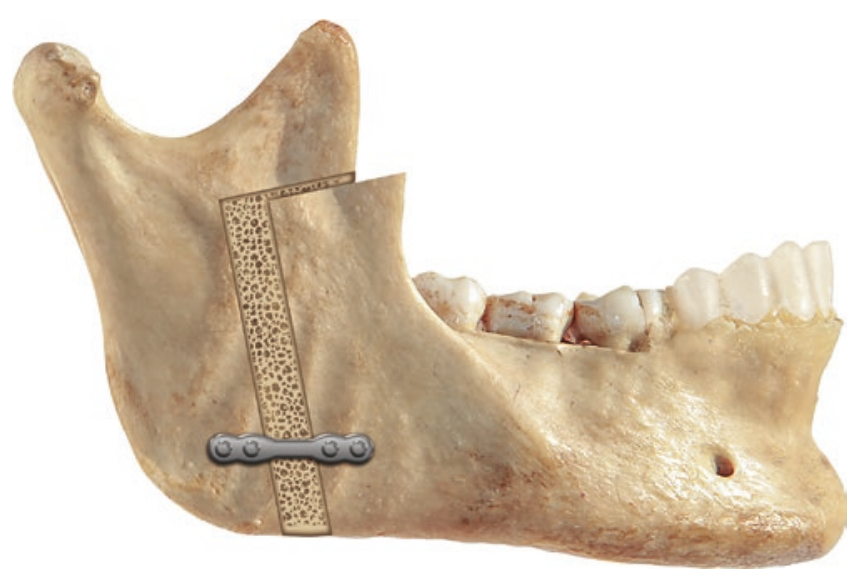

CAssociation of Oral and Maxillofacial Surgeons of India

Fig. 68.6 Inverted "L" osteotomy of the ramus used for advancing the mandible

\subsubsection{Extraoral Vertical Ramus Osteotomy}

This was one of the most popular procedures for correcting mandibular prognathism. Rigid internal fixation techniques and certain modifications like "C" osteotomy and inverted "L" osteotomy have been used for advancement of the mandible. After "C" or "L" osteotomy, the gap created while advancing or rotating the distal segment is filled with bone graft [10].

The major disadvantages are the external scar and the possible inadvertent damage to the marginal mandibular nerve. With judicious care, these problems can be minimized. Better visibility is the major advantage (Fig. 68.7).

\section{Surgical Technique:}

Submandibular skin incision is placed, about $1.5 \mathrm{~cm}$ below the angle of the mandible. The incision is taken down to the platysma, which is then divided. Marginal mandibular nerve lies below the platysma running parallel to and often below the lower border of the mandible, crossing the facial vessels superficially as it passes upward. Attempt should be made to identify this structure and preserve it.

After identification and protection of the marginal mandibular nerve, dissection is carried down to the bone. The periosteum is incised over the angle. The periosteum is reflected superiorly to the level of the sigmoid notch on the lateral aspect of the ramus. Coronoid process may be cut in cases when more than $1 \mathrm{~cm}$ of posterior movement is required (Fig. 68.8).

Lateral aspect of the ramus is inspected for a small bulge corresponding to the lingula. This helps to identify the mandibular foramen. Osteotomy is performed posterior to the anti-mandibular foramen bulge so that the mandibular nerve is not injured. (The position of the bulge is arbitrary and not definite.) A vertical bony cut is made starting at the sigmoid notch and progressing to the lower border near the angle of the mandible. Condylar segment is separated from the distal part of the mandible and is detached from the medial pterygoid muscle. The condylar part is

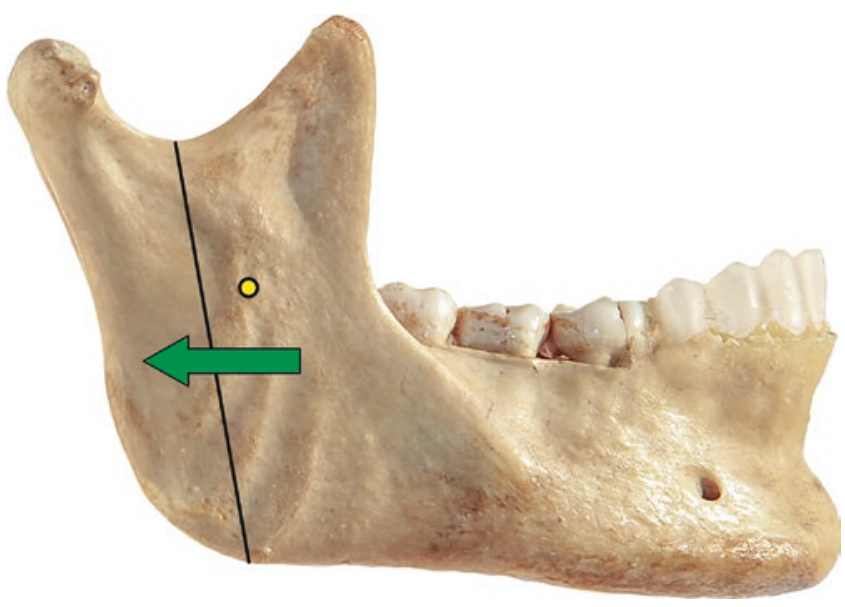

CAssociation of Oral and Maxillofacial Surgeons of India

Fig. 68.7 Subsigmoid vertical osteotomy was the most popular technique before the introduction of sagittal split osteotomy. This technique is used for correcting mandibular prognathism 


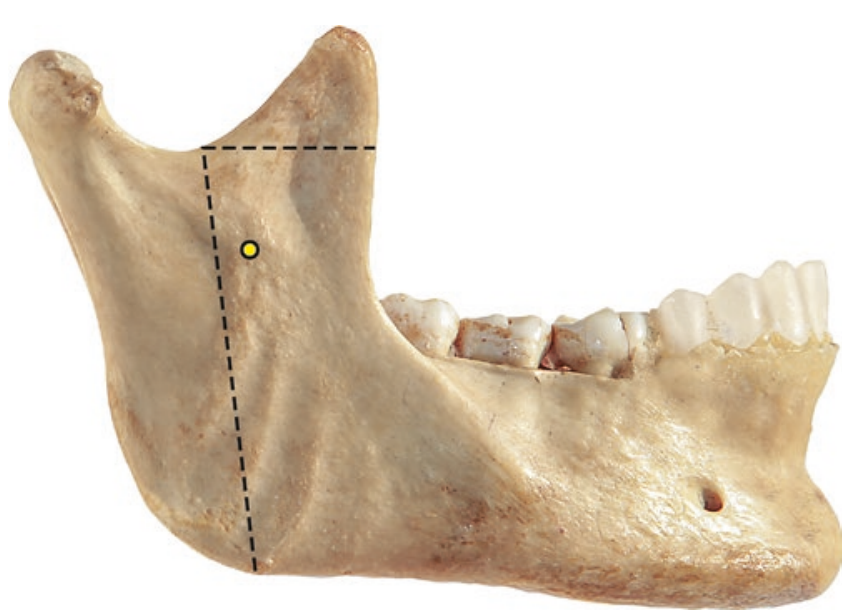

CAssociation of Oral and Maxillofacial Surgeons of India

Fig. 68.8 When the push back required in subsigmoid vertical osteotomy is more than $1 \mathrm{~cm}$, sectioning of the coronoid process helps in better stability

laterally placed on the distal segment. After packing the wound, the same steps are followed on the contralateral side.

The mandible is repositioned into the desired position with the help of the splint, and intermaxillary fixation is done. The site of surgery is again approached. Some surgeons prefer to leave the condyle as such on the lateral aspect without any transosseous wiring. There is no consensus regarding the decortication of the opposing surfaces.

Removal of bone or decortication may be done if it helps the condyle to achieve a proper position within the glenoid fossa with minimal displacement. Decortication helps better contact of the cancellous bone enhancing healing. Stabilization of the fragments by transosseous wires or screws and plates can be done. Rigid internal fixation eliminates intermaxillary fixation. Except in rigid internal fixation, intermaxillary fixation for a period of 4-6 weeks is mandatory. After the fixation is removed, elastics may be used to guide the movements.

Wound closure is done in layers. Skin may be closed by monofilament 6-0 or smaller sutures. A pressure dressing is applied for the first $24-48 \mathrm{~h}$. Drain is usually not necessary and, if done, has to be done through a separate stab incision below the main incision. Sutures are removed after 5-7 days, and the wound is supported by dressing for a period of another 1 week, if required.

Complications are usually rare. Bleeding may occur due to injury to the retromandibular vein or masseteric artery where it crosses laterally through the sigmoid notch. Bleeding can be controlled by routine methods like pressure packs, ligation, etc. Injury to the marginal mandibular nerve is another possibility. A transitory deficiency in the function of the lower lip may be anticipated due to traction on the nerve. This often recovers completely. In case of sectioning of the nerve, micro-surgical repositioning is advised.

If care is taken in closure, and infection is avoided, scar formation is minimal. If scar is formed, revision may be done subsequently (Fig 68.9a-d).

\subsubsection{Sagittal Split Osteotomy}

Sagittal split osteotomy (SSO) can be employed for correcting both retrognathism and prognathism. Modifications by Dal Pont, Hunsuck, and Epker have made the procedure simpler and more acceptable biologically. Schuchardt and Lane described sagittal split osteotomy of the vertical ramus [11]. It was Obwegeser who popularized it. His medial cut was above the mandibular foramen, and his lateral cut was below that of Schuchardt's and extended to a part just above the angle, at least $25 \mathrm{~mm}$ below the lingual cortical cut. Obwegeser and Trauner in 1955 described the bilateral sagittal split osteotomy [6].

Dal Pont in 1961 made a major modification by extending the cut anteriorly and making the vertical cut just below the second molar [8]. Hunsuck in 1968 modified the cut in the medial cortex of the vertical ramus, limiting the cut to just behind the mandibular foramen. Postoperative complications got reduced [9] (Fig. 68.10a, b).

Bell and Schendel and Epker extended the vertical cut on the buccal side to the lower border of the mandible reducing the incidence of wrong splits $[12,13]$. A reciprocating osteotomy saw, which is specifically meant for the inferior border (right and left) may be used to perform inferior border osteotomy [14].

Performing an inferior border osteotomy results in much lower incidence of persisting inferior border defects. Hence, during advancement of the mandible, it is advisable to exclude the lingual cortex in the split. Piezosurgery has been compared with conventional surgical drills/saws by several authors for BSSO. They have reported substantially longer surgery time for piezosurgery. Image-guided surgery has also become popular in the recent years, and this allows the surgeon to track the position of the instruments and segments during the operation in real time. Modern intraoperative navigation systems are being used in orthognathic surgery also [15].

A. Incision and Dissection:

Incision is placed over the region of the ramus to the mid ramus. It is carried over the external oblique ridge, extends up to the first molar region, and curves down to the buccal vestibule.

Initially only the mucosa is incised over the ramus region. Retracting the tissue buccally, before incision, prevents the exposure of the buccal pad of fat, a troublesome interference, during surgery. Sharp dissection at the ramus is continued to the periosteum, using scissors, knife, and periosteal elevators.

Periosteal elevation of the lateral aspect of the mandible at the molar region is performed down to the inferior border. On the ramus, lateral dissection may be kept minimal but enough to achieve proper visibility and access.

Medial dissection is done very carefully on the medial side of the ramus. The level of the lingula and the entry of the inferior alveolar nerve into mandibular foramen are visualized. This is usually in level with the deepest concavity along 
Fig. 68.9 Mandibular prognathism corrected by subsigmoid vertical osteotomy of the ramus on both sides to set back the mandible. (a, b) Preop pictures, $(\mathbf{c}, \mathbf{d})$ postop pictures
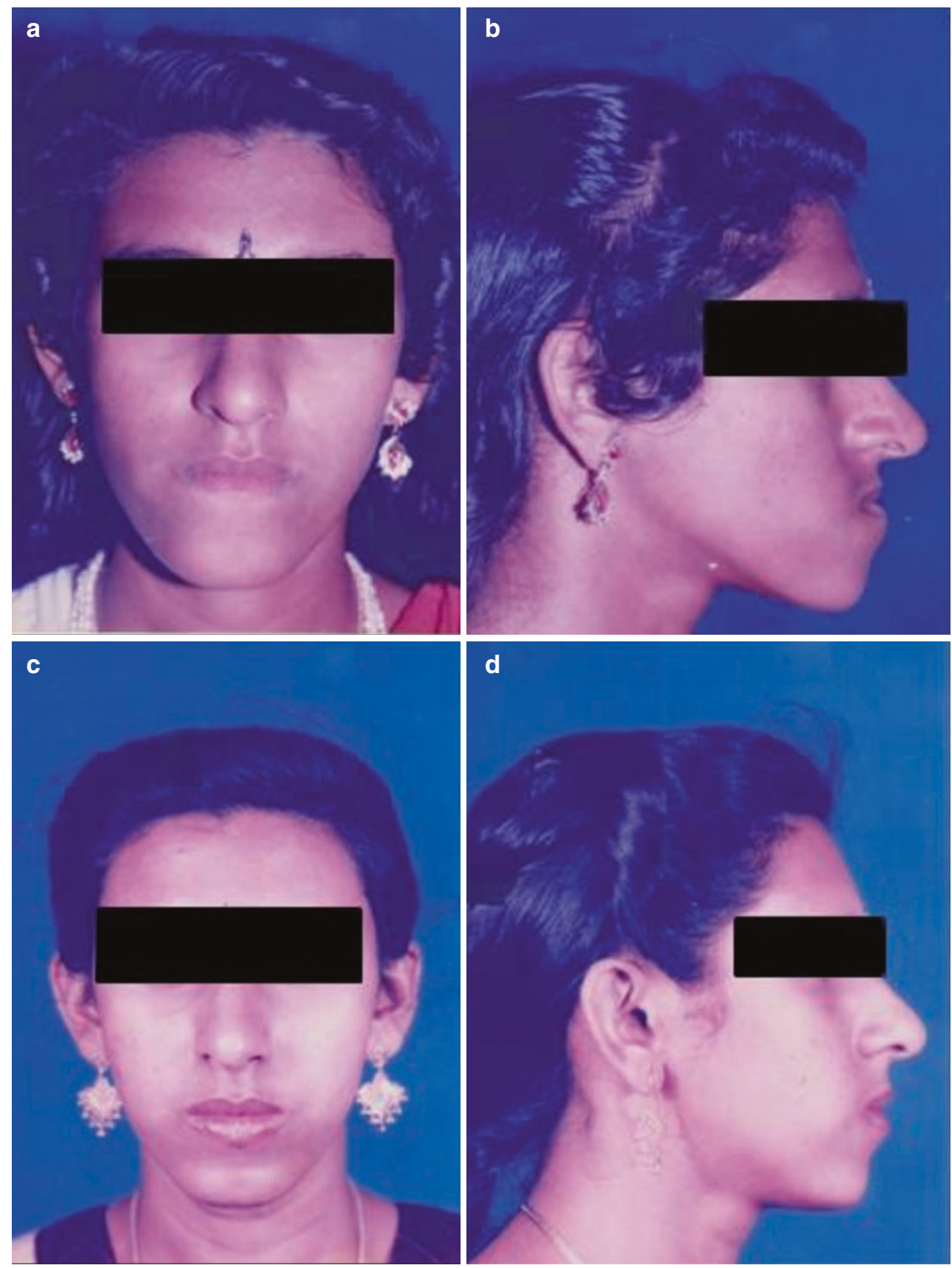

CAssociation of Oral and Maxillofacial Surgeons of India the anterior border of the coronoid and ramus. With a small flexible Freer Elevator, the tissue is dissected taking care not to perforate the periosteum on the medial aspect. Dissection should be above the level of the mandibular foramen. Using a bigger elevator, the medial aspect of the mandible above the lingula is exposed subperiosteally. (Perforation of the periosteum not only induces bleeding but may injure the mandibular nerve.) Sigmoid notch is identified for better orientation. Subperiosteal dissection should be minimal, but enough to retract the tissues medially without much traction on the mandibular neurovascular bundle [16].

B. Osteotomy (Videos 68.1 and 68.2):

Osteotomy is initiated by cutting the cortical bone above the lingula on the medial side. This cut should extend behind the mandibular foramen but need not be up to the posterior border of the ramus (about half to two-thirds of the anteroposterior dimension of the ramus). The cut is taken downward along the external oblique ridge to the second or first molar region. The depth of the cut should be minimal, just enough to reach the cancellous bone (Figs. 68.11 and 68.12).

Conventionally the vertical cut is made at the second molar region as the bone is thicker there. The $\mathrm{CT}$ analysis conducted by $\mathrm{Y}$ Tsuji et al. on prognathic mandible demonstrated that the mandibular thickness of the mandible increased along the mandibular foramen toward the mandibular body. The mandibular canal was located relatively lingually at all sites. They also observed that marrow space, located on the buccal side, was thicker at the region of mandibular body [17]. 
a

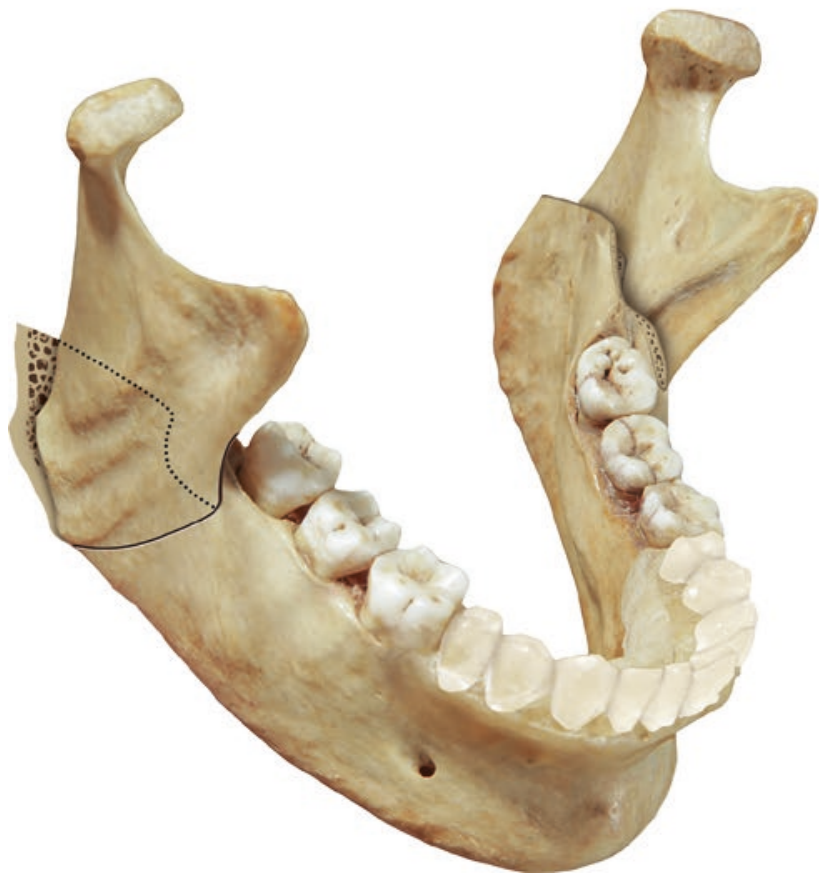

CAssociation of Oral and Maxillofacial Surgeons of India

Fig. 68.10 Bilateral Sagittal Split Ramus Osteotomy (BSSO/BSSRO). (a) Obwegeser split: Initially the medial cut in sagittal split osteotomy extended up to the posterior border, and when the distal segment was pushed back, the margin used to jut out, which had disadvantages like

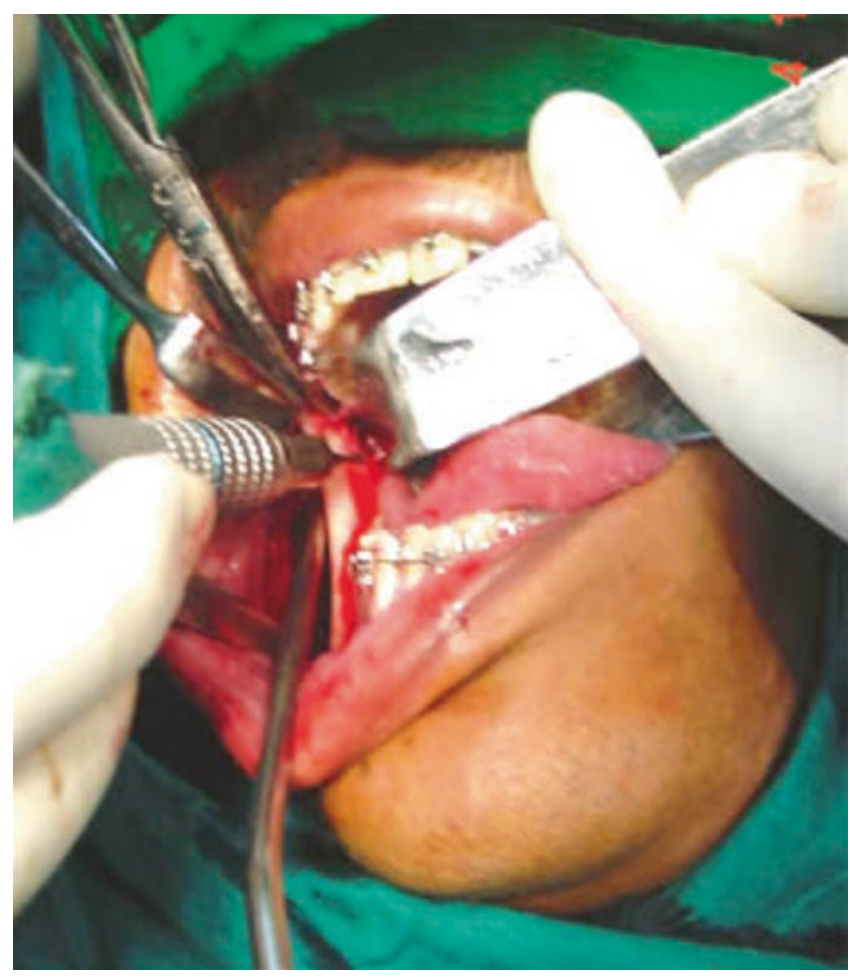

CAssociation of Oral and Maxillofacial Surgeons of India

Fig. 68.11 The medial cut is taken above and behind the mandibular formen and deepened to the cancellous bone b

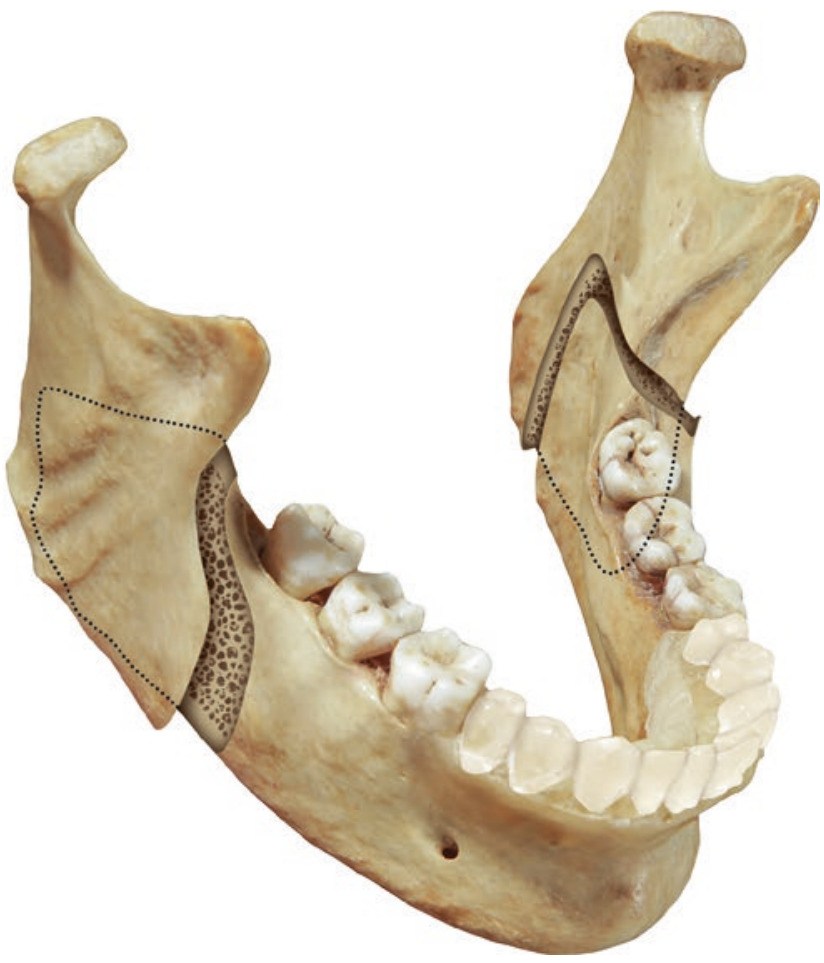

relapse tendency and injury to the retromandibular tissues. (b) Hunsuck split: At present the medial cut is taken above the mandibular foramen much short of the posterior border but behind the foramen. The complications are much less (also see Fig. 65.12b)

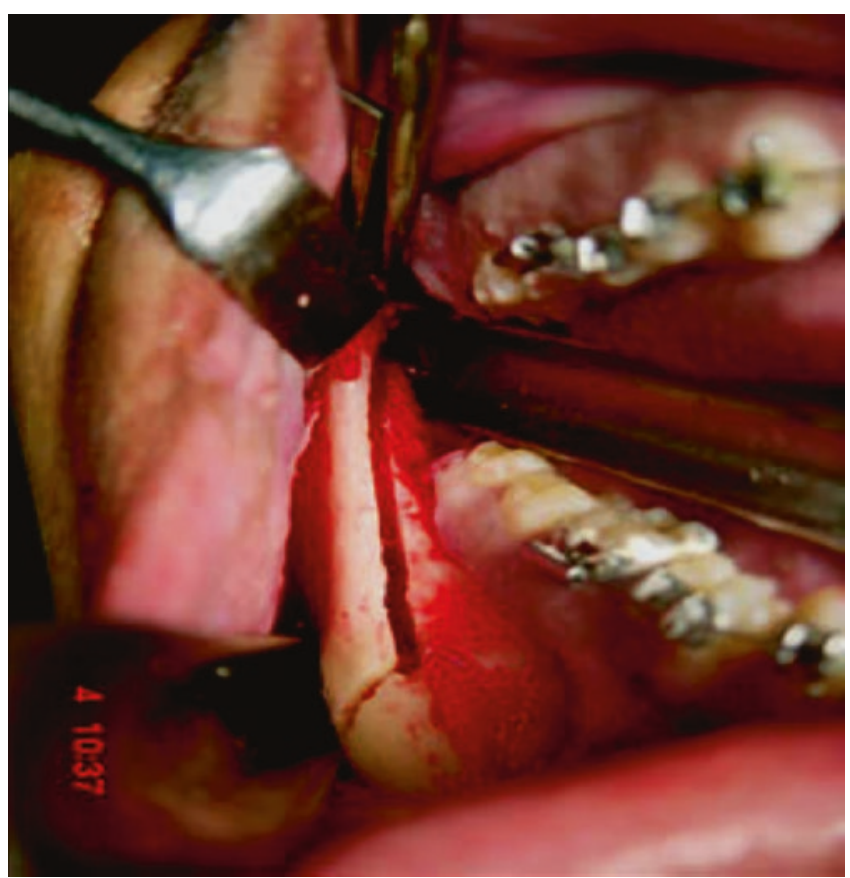

CAssociation of Oral and Maxillofacial Surgeons of India

Fig. 68.12 The cut is extended obliquely through the anterior border of the mandible to the buccal plate and taken downward at the level of the first or second molar region, up to the inferior border. Only the cortex need be cut. Deeper cuts could injure the inferior alveolar nerve and may cause wrong splits (also see Figs. $69.31 \mathrm{a}-\mathrm{c}$ and $70.24 \mathrm{c}, \mathrm{d}$ ) 
A study on cadaveric mandible by Promma et al. reported that the thickness of buccal cortex to the mandibular canal is about 6.5 and $5 \mathrm{~mm}$ at the second molar and first molar regions, respectively [18].

Some surgeons prefer to take the cut more forward to the first molar region. This gives better accessibility for intraoral plating. When the vertical cut is made, it is mandatory to protect the soft tissue over the inferior border by using a channel retractor. If the vertical cut includes the inferior border, the direction of the split is controlled. A rotary instrument or a reciprocating saw is used for cutting. Once the cortical cut is completed, a small spatula osteotome is malleted to the site beginning from the medial cut to the vertical cut. Osteotome should be directed laterally just beneath the cortical plate so that the neurovascular bundle is not injured. Larger osteotomes are used, and slowly the fragments are pried apart using a smith spreader (Fig. 68.13).

As the splitting takes place, the neurovascular bundle is visualized, and care is taken to maintain it to the medial fragment. If it is attached to the proximal segment, the NV bundle is freed with a periosteal elevator. Next the fragments are pried apart using the spreader. The procedure is repeated on the opposite side.

Sagittal split osteotomy can be used for either mandibular advancement or setting back. If mandibular advancement is to be done, the medial pterygoid muscle is separated from the inferior border of the distal segment with a periosteal elevator. When the mandible is set back, medial pterygoid and masseter may have to be stripped, if needed, to prevent the displacement of the condylar segment posteriorly. Posterior stripping of the pterygomasseteric sling in SSO should be minimized to the antegonial notch. In excessive stripping, possibility for avascular necrosis increases [19].

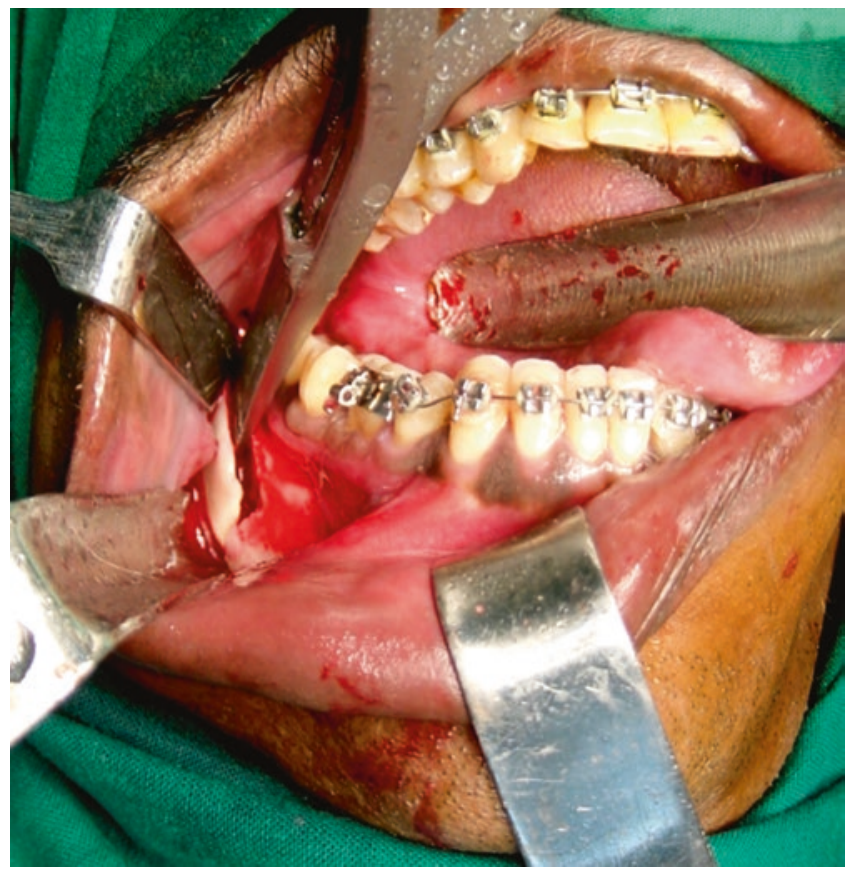

(CAssociation of Oral and Maxillofacial Surgeons of India

Fig. 68.13 A spreader is used to split the mandible at the ramus region
When the tooth bearing segment (distal segment) is pushed back, the buccal plate of the condylar segment (proximal segment) overlaps the distal. This overlapping part is excised, and the proximal segment is allowed to rest on the cancellous part without any tension (Fig. 68.14).

Pushing the mandible backward reduces the space in the oral cavity. The tongue may not have enough space, and sometimes this induces tongue thrusting, snoring, etc. Some authors advocate reduction glossectomy to improve function related to airway speech and mastication. They also opine that reduction glossectomy improves aesthetics and controls unfavorable mandibular growth [20].

Mommaerts reported that mandibular lengthening done through endoscopic surgery, with transoral osteosynthesis, reduced stripping of the periosteum and therefore consequent edema [21]. In certain clinical situations Unilateral sagittal osteotomy is performed. Refer case scenario in Fig. 69.31 (Maxillary orthognathic surgery Chap. 69) where an unilateral sagittal osteotomy was combined with maxillary osteotomy to correct canting of the maxilla.

C. Stabilization and Fixation:

Rigid internal fixation (RIF) using plates and screws or lag screws is the preferred way of fixation. Prior to RIF, the position of the jaw is adjusted, and intermaxillary fixation is done with splint in position. Both fragments are allowed to be in passive position before RIF is performed. Intermaxillary fixation (IMF) is removed after rigid fixation. However, some surgeons prefer to keep the IMF for 1 week. For rigid fixation $2.5 \mathrm{~mm}$ four-hole mini plate with gap is used for push back (Fig. 68.15). Longer plates are used for advancement. Multiple lag screws can also be used. Skeletal rigid fixation has been shown to reduce relapse following mandibular advancement [22-24] (Figs. 68.16a, b, c, and 68.17a, b, c).

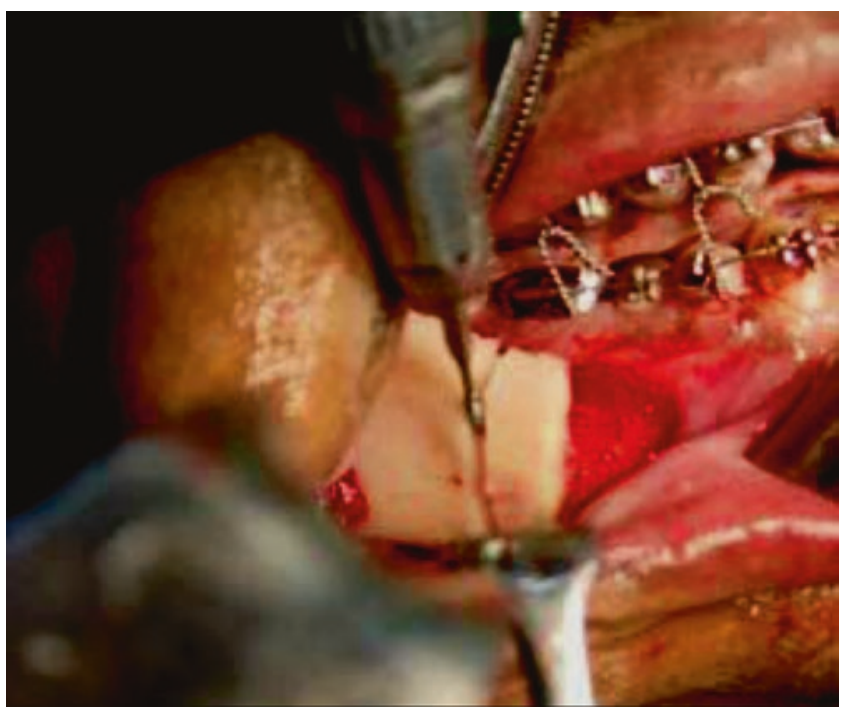

CAssociation of Oral and Maxillofacial Surgeons of India

Fig. 68.14 Excess of the buccal plate is cut off when the intention is to push the mandible backward 
Rachmiel et al. in their study found improved stability with four-hole plate and monocortical screws, with a relapse rate of about $18 \%$ only [25].

Based on a 10-year experience of using bioresorbable plates in orthognathic surgery, Laine $\mathrm{P}$ et al. opine that these devices are safe to be used. Relapse rate with bioresorbable screws is the same as with metal in SSO [26]. Another method of fixation is wiring. If resorting to wiring, intermaxillary fixation has to be kept for 5-6 weeks. Maturation of soft and bony

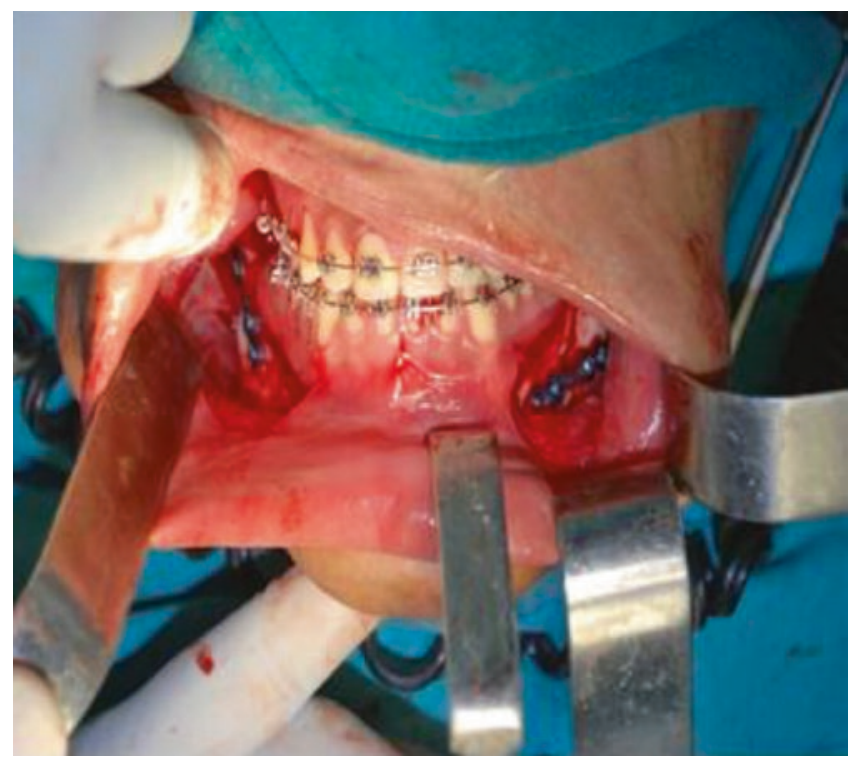

CAssociation of Oral and Maxillofacial Surgeons of India

Fig. 68.15 Rigid fixation after sagittal split osteotomy of the mandible using mini plate tissues continues at the surgical site and approximates that of non-surgical sites at 12 weeks postoperatively [27-29].

The inferior alveolar nerve is less likely to get damaged when monocortical screws are used. These screws also allow for readjustment if there is any inadvertent malposition during surgery can be readjusted more easily [30]. An in vitro study on sheep mandibles found that both mini plates and bicortical screws resulted in a similar level of stability [31]. (Figs. 68.18a, b, c, d, 68.19a, b, c, and 68.20a, b, c).

D. Wound Closure:

Wounds are irrigated well and bleeding is controlled by routine methods. If there is continued bleeding drain is indicated. Wounds are closed by 3-0 Vicryl sutures.

E. Postoperative Sequelae:

Edema is expected after sagittal split osteotomy. It resolves within 2 weeks. Edema at the angle is the last to resolve. Suction drainage minimizes tissue edema following mandibular surgeries. Betamethasone administration significantly reduces postoperative edema. Widar $\mathrm{H}$. et al. has also observed less bleeding intraoperatively, but no difference in neurosurgery disturbances [32].

Diminished sensation over the lip is experienced by most of the patients and is mainly due to traction on the neurovascular bundle. If there is no injury to the neurovascular bundle, sensation returns within a few weeks. More than two-thirds of the patients experience some sensory deficit even after 1 year. However, most of the patients get adjusted to this altered sensation and are satisfied with the overall result. Limitation of movements of jaw in all direction after osteotomy is often experienced. Sagittal split advancements often cause significant limitation of range of motion [33].
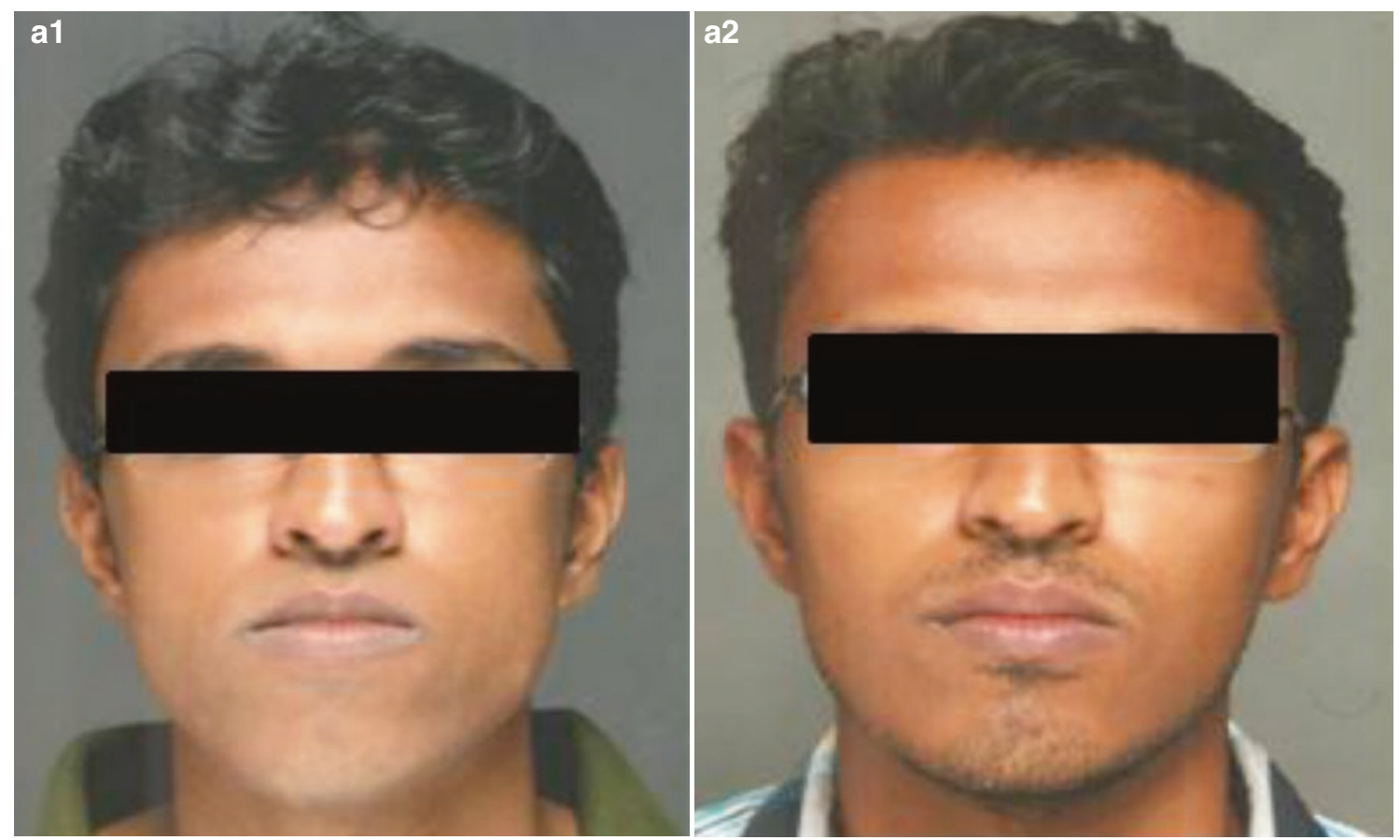

Fig. 68.16 Bilateral sagittal split osteotomy to set back the mandible, with rigid fixation. (a1, b1) Preoperative photographs. (a2, b2) Postoperative photographs. $(\mathbf{c 1}, \mathbf{c 2})$ Pre and post operative lateral cephalograms with superimposed tracings 

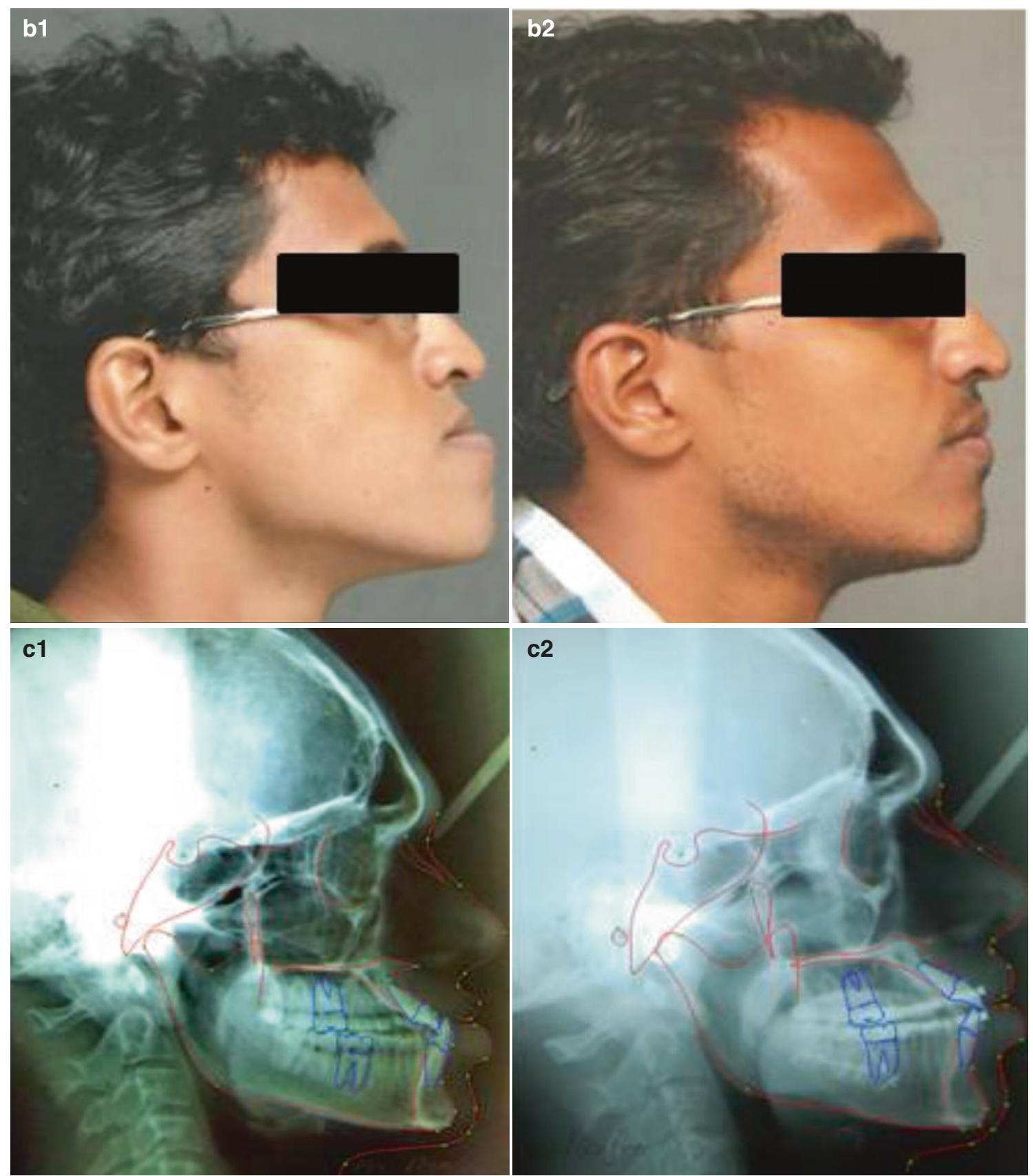

OAssociation of Oral and Maxillofacial Surgeons of India

Fig. 68.16 (continued)

Physiotherapy following rigid fixation showed minimal limitation [34].

F. Complications:

Important complications associated with sagittal split osteotomy are:

1. Bad split

2. Injury to the neurovascular bundle

3. TMJ problems

4. Excessive bleeding

5. Relapse

\section{Bad Split:}

A systematic review of fracture patterns in sagittal split was analyzed by Steenen and Becking and reported 2.3\% bad splits in sagittal splits. The most common was buccal plate fracture of the proximal segment and lingual plate fracture of the distal segment. Coronoid and condylar neck fractures were seldom [35].

Wrong split usually occurs in cases where the last molar is removed at the time of surgery. Hence it is advised to have the third molar removed (if needed) about 6 months 

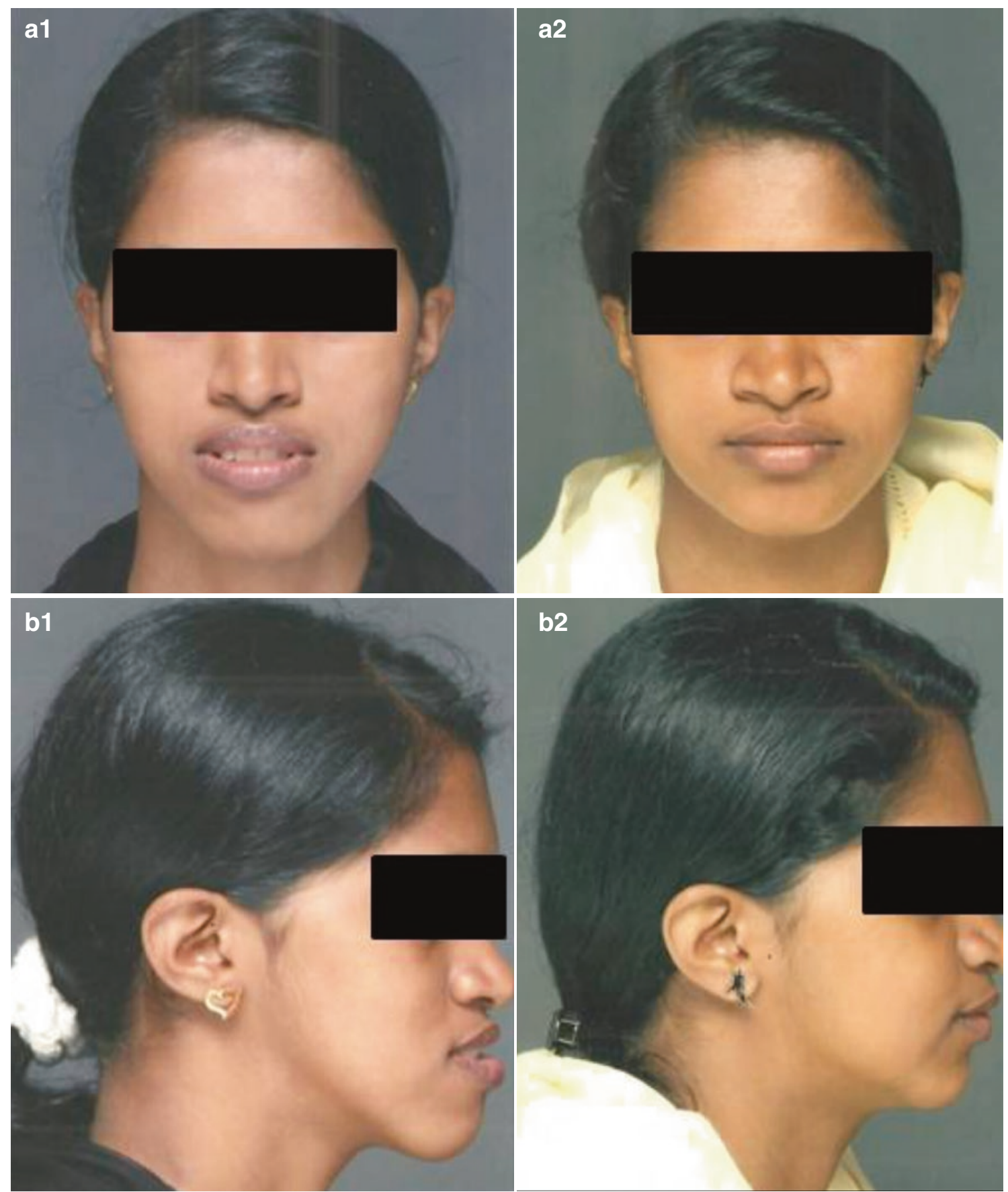

Fig. 68.17 Case of mandibular prognathism with maxillary deficiency, managed by maxillary advancement and mandibular set back by BSSO. (a1, b1) Preop pictures. (a2, b2) Postop pictures. (c1) Preop cephalogram. (c2) Postop cephalogram

prior to the osteotomy. If the lingual cortical plate is broken, soft tissue separation from the lingual plate should be kept to the minimum, so that the blood supply is not jeopardized. Patients with a shorter ramus and buccolingually thin mandible are more susceptible to wrong split during SSO [36]. Advanced age can increase the risk of a bad split. Use of a spreader helps to reduce the incidence of wrong splits.

\section{Injury to the Neurovascular Bundle:}

Care should be taken to maintain the continuity of the neurovascular bundle. If it is transected, ideally the cut ends are micro-anastomosed. However, in common practice, where a micro-surgeon may be unavailable, it is advisable to perform direct suturing to attain epineural approximation. With a repositioned and repaired neurovascular bundle, the sensation is recovered though the period it takes is longer. 

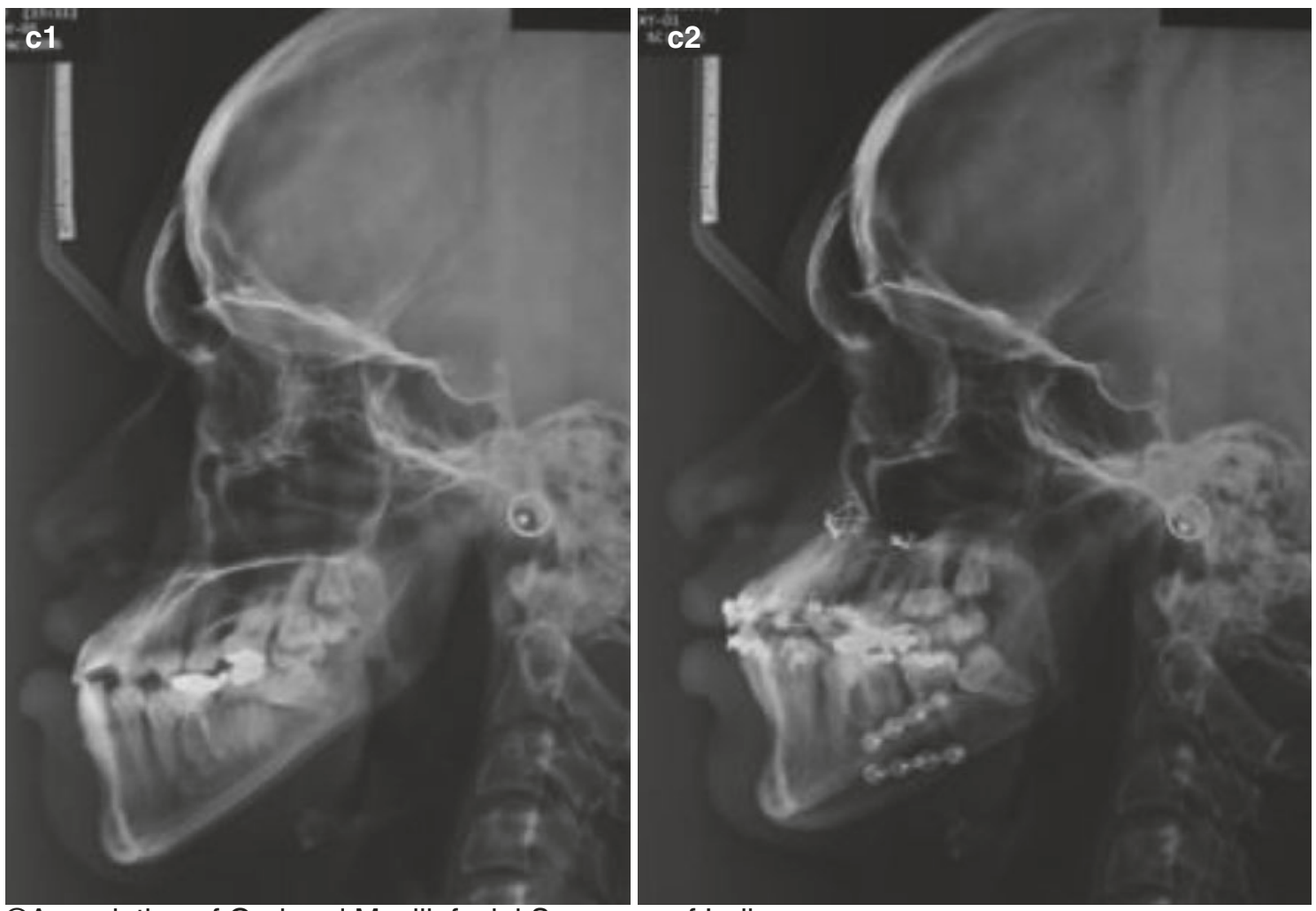

(c)Association of Oral and Maxillofacial Surgeons of India

Fig. 68.17 (continued)

Long-lasting neurosensory deficiency (NSD) was underestimated by the surgeons as compared to the patient's subjective symptoms. Long-lasting NSD was reported as $7.5 \%$ (Questionnaire) and 3.8\% (Record), after intraoral vertical ramus osteotomy, and as $11.6 \%$ (Questionnaire) and $8.1 \%$ (Record) after sagittal split osteotomy [37]. Vertical subsigmoid osteotomy with rigid fixation may be considered as a viable alternative if it is important to avoid alterations in sensation, whereas BSSO maybe preferred if retromandibular scar is of concern. Neurosensory disturbance, after SSO with additional genioplasty, is more than after SSO alone [38].

\section{TMJ Problems:}

Care should be taken while plating the segments. Improper plating can pull or push the condyle to an untoward position. Postoperative X-rays are taken to assess the situation. If needed, the displacement has to be corrected by returning the patient to surgery. Displacement of the condyle from the fossa is one of the main reasons for relapse [24, 39] (Fig. 68.21).
Beukes J. et al. in 2016 studied condylar rotational tolerance in BSSO treatments and reported a range of $10^{\circ}-15^{\circ}$ after orthognathic surgery.

Unilateral SSO is a safe procedure in lateral prognathism of mandible due to unilateral condylar hyperplasia or traumatic malocclusions [40]. The condyle that was not operated on, only rotated $3-4^{\circ}$ within the glenoid cavity, and it was established that this is within the range of functional articular adaptation [41]. Mendez-Manjon R. et al. observed that mandibular advancement by BSSO can positively displace the condyle especially on the posterior aspect [42].

In their study Borstlap et al. observed that in sagittal split advancement postoperatively, $8 \%$ of patients showed postoperative condylar resorption. Patients of relatively low age are at risk of condylar alterations or resorption. Occurrence of pain and TMJ sounds in the first few months postoperatively are highly indicative of condylar changes to occur in the preceding months [43]. Predisposition in females for condylar resorption after sagittal split osteotomy may be attributed to 

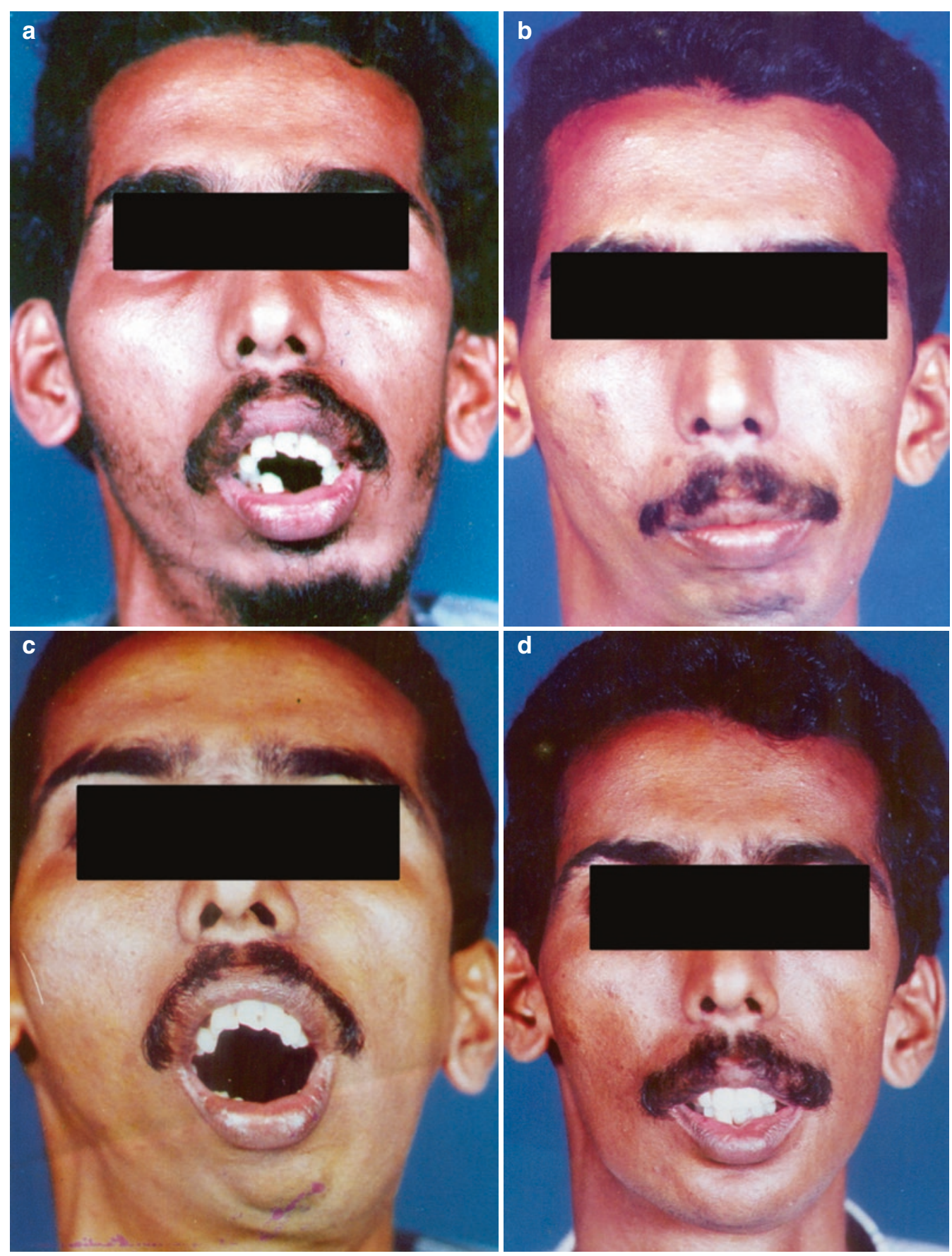

OAssociation of Oral and Maxillofacial Surgeons of India

Fig. 68.18 A case of left unilateral ankylosis of the TMJ resulting in trismus and facial deformity. Treated by release of ankylosis by gap arthroplasty, temporal myofacial flap interposing, and extended lateral sliding genioplasty. (a) Pre operative picture before ankylosis correction (b) frontal view with facial asymmetry (c) after release of ankylosis, (d) after correcting facial asymmetry 
the modulation of biologic response, by estrogen and prolactin [44]. Mobarak compared the skeletal stability of postoperative changes in low angle and high angle $\mathrm{Cl}$ II patients following mandibular advancement. High angle had more horizontal skeletal relapse due to condylar movement in a superior direction. Changes in intercondylar angle and width after BSSO advancement or set back may influence TMJ function [45-48].

4. Excessive Bleeding:

Bleeding can be from inferior alveolar neurovascular bundle, medullary bed, and facial vessels or rarely from retromandibular vein. Bleeding from the former two can be controlled by local measures; but the facial vessels will have to be clamped and tied, for which an extraoral incision may be required. Using the channel retractor with a cup to hold the inferior border and cutting with a Steiger-type carbide bur (this has side cutting and rounded cutting end and cuts bone with minimal injury to the soft tissue) prevents injury to the facial vessels.

Injury to the retromandibular vein is very rare and is due to inadvertent injury to the soft tissues behind the mandible. Bleeding can be controlled by absorbable gelatin sponge. Excessive oozing can cause significant edema, and if oozing is present, a drain may be placed.
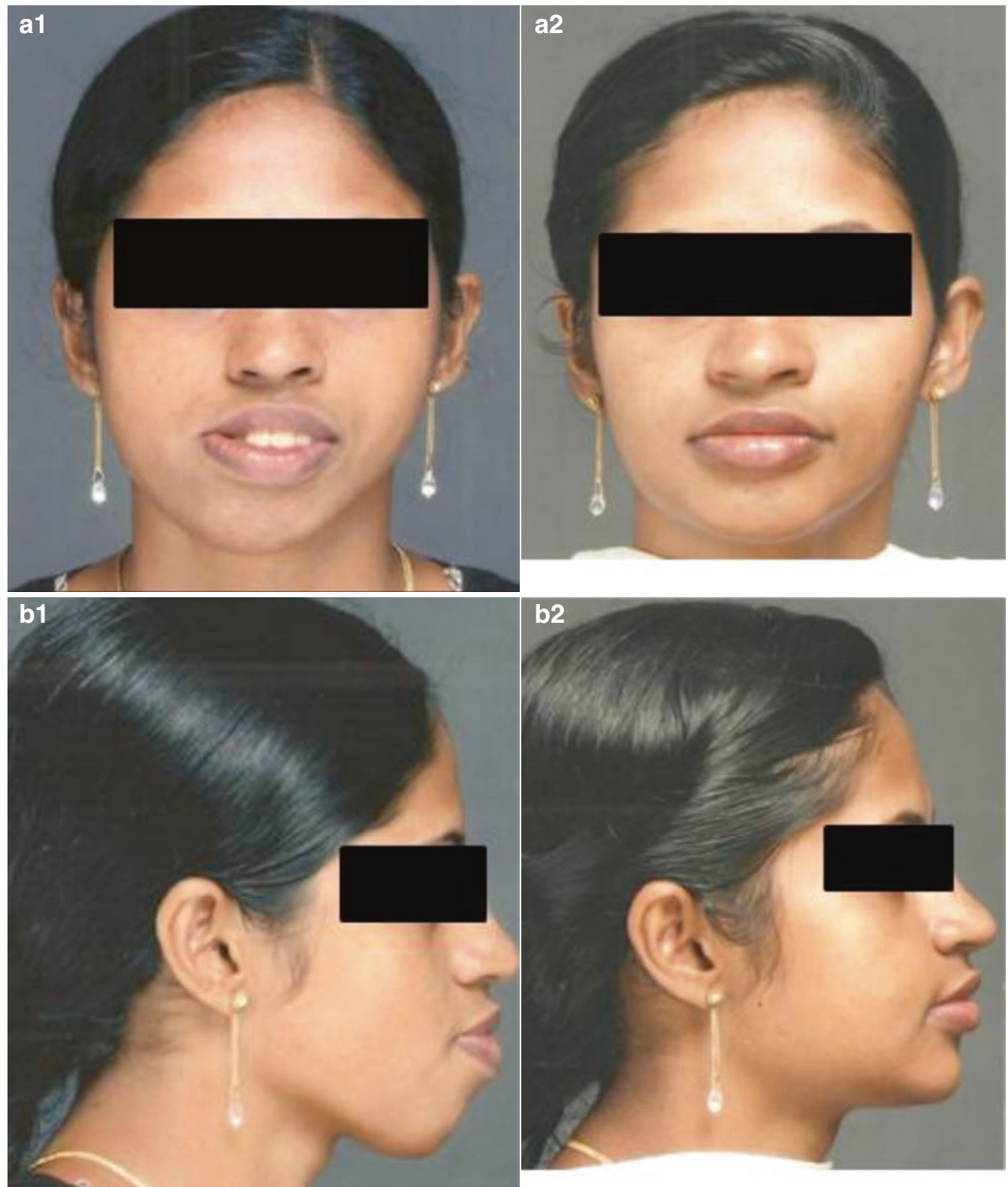

Fig. 68.19 Facial asymmetry and vertical and sagittal excess of maxilla corrected by LeFort1, anterior maxillary osteotomy, bilateral sagittal split osteotomy and advancement genioplasty. (a1, b1) Preoperative pictures. (a2, b2) Postoperative pictures. (c1) Preoperative lateral cephalogram. (c2) Postoperative lateral cephalogram 


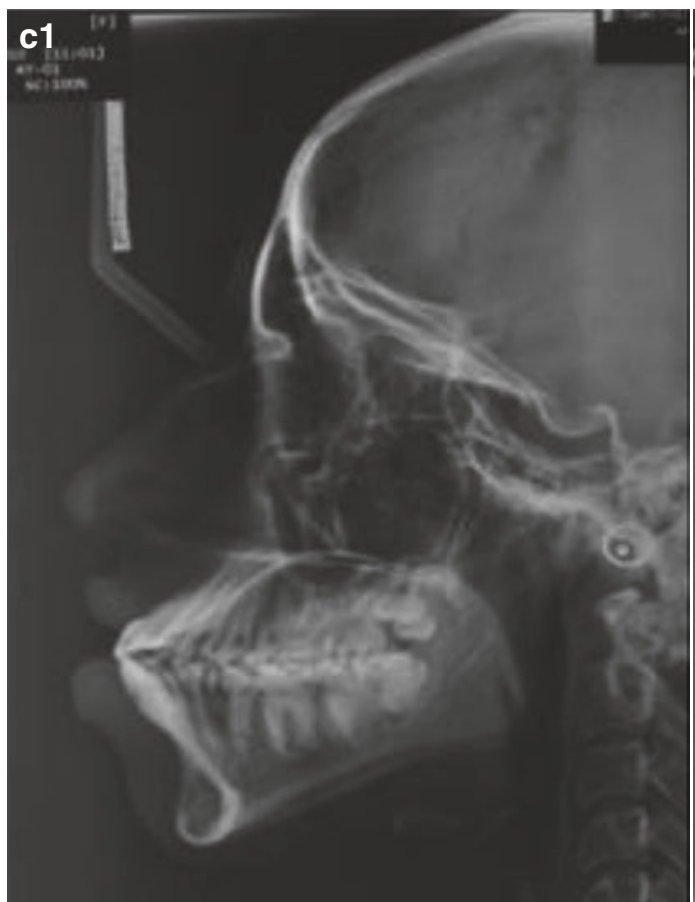

CAssociation of Oral and Maxillofacial Surgeons of India

Fig. 68.19 (continued)

\subsubsection{Vertical Ramus Osteotomy: Intraoral Approach}

It was Caldwell and Letterman who developed the intraoral vertical ramus osteotomy in 1954 [3]. Later in 1964, this was described by Moose [49] and Winstanley in 1968 [50], and modifications have been suggested by many others. Intraoral approaches medially and laterally to ramus were described $[49,50]$. Herbert and associates in 1970 described the use of special oscillating saw and popularized the intraoral technique to reach the ramus (Fig. 68.22).

The procedure overcomes the disadvantages of extraoral vertical ramus osteotomy. The advantages are the following: (1) external scar is avoided and (2) there is no injury to the marginal mandibular nerve. The advantages over sagittal split osteotomy are that injury to the mandibular neurovascular bundle is avoided. The main disadvantage is the difficulty in access and visualization of the area. However, there is a delay in healing and possibility of projection of antegonial notch [51]. Mandibular nerve hypoesthesia can be expected to improve faster in young patients than the older ones. So IVRO may be a better option for elder patients [52].

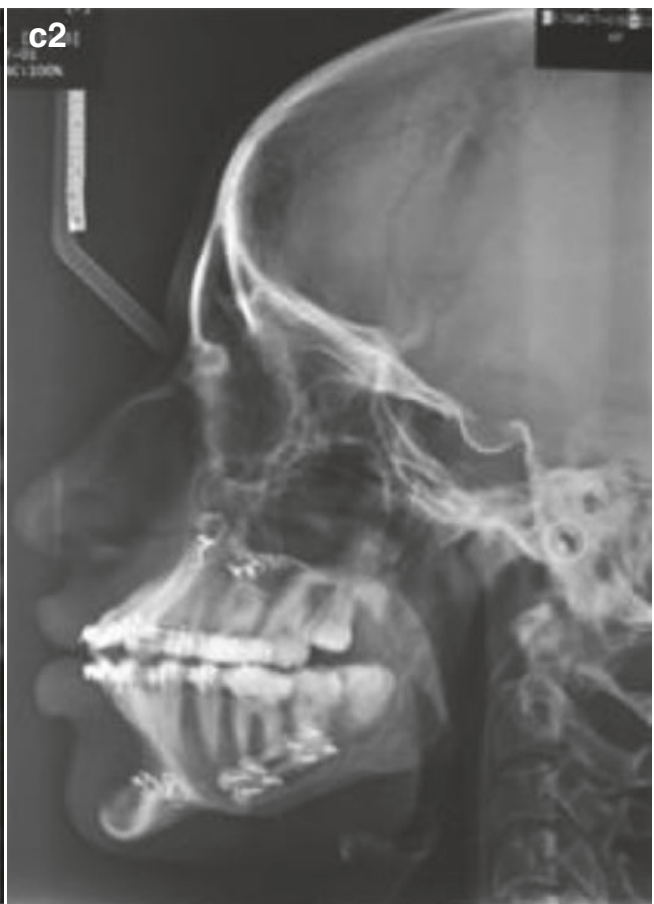




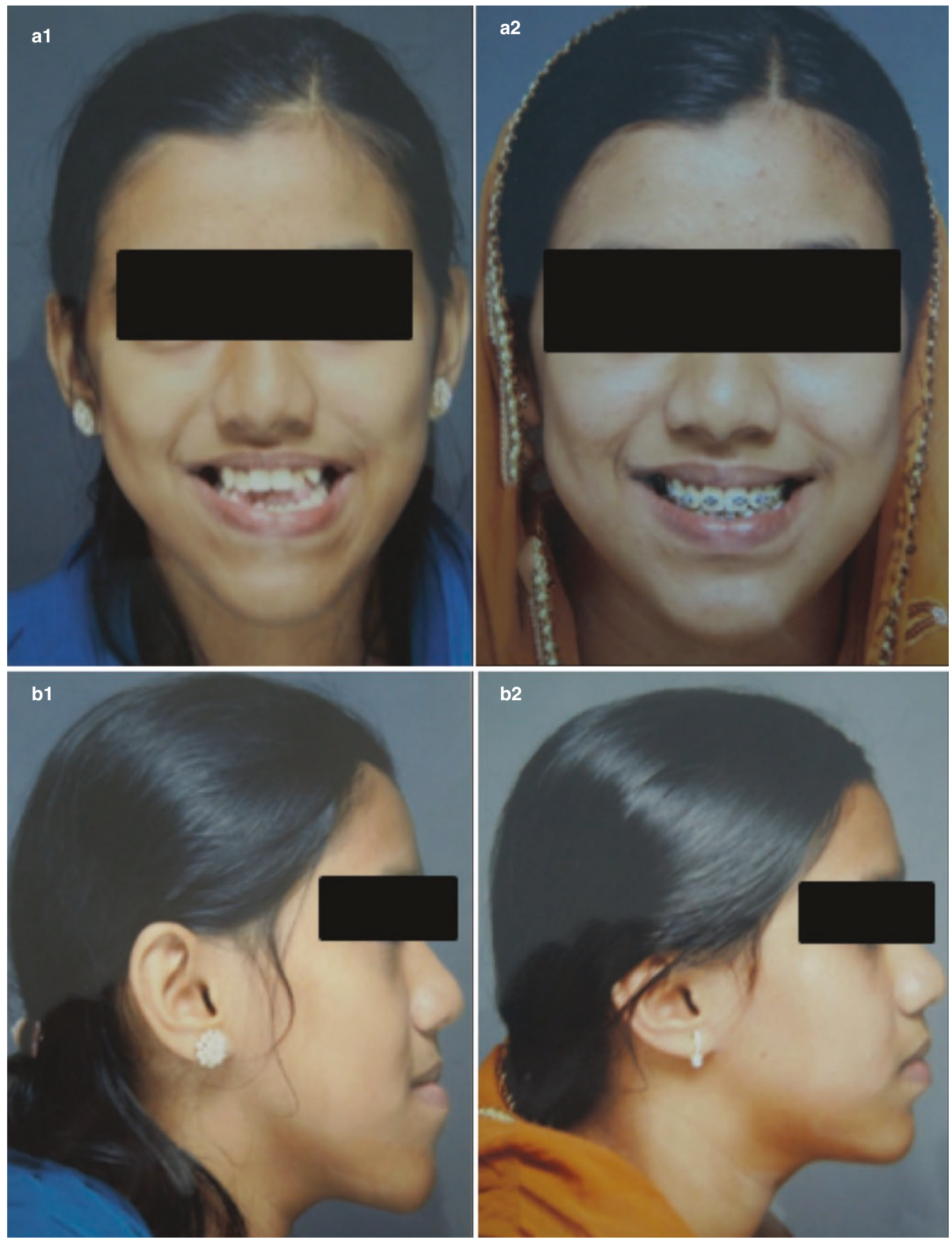

Fig. 68.20 Case of open bite managed by BSSO. (a1, b1) Preoperative pictures. (a2, b2) Postoperative pictures. (c1) Preoperative lateral cephalogram. (c2) Postoperative lateral cephalogram 


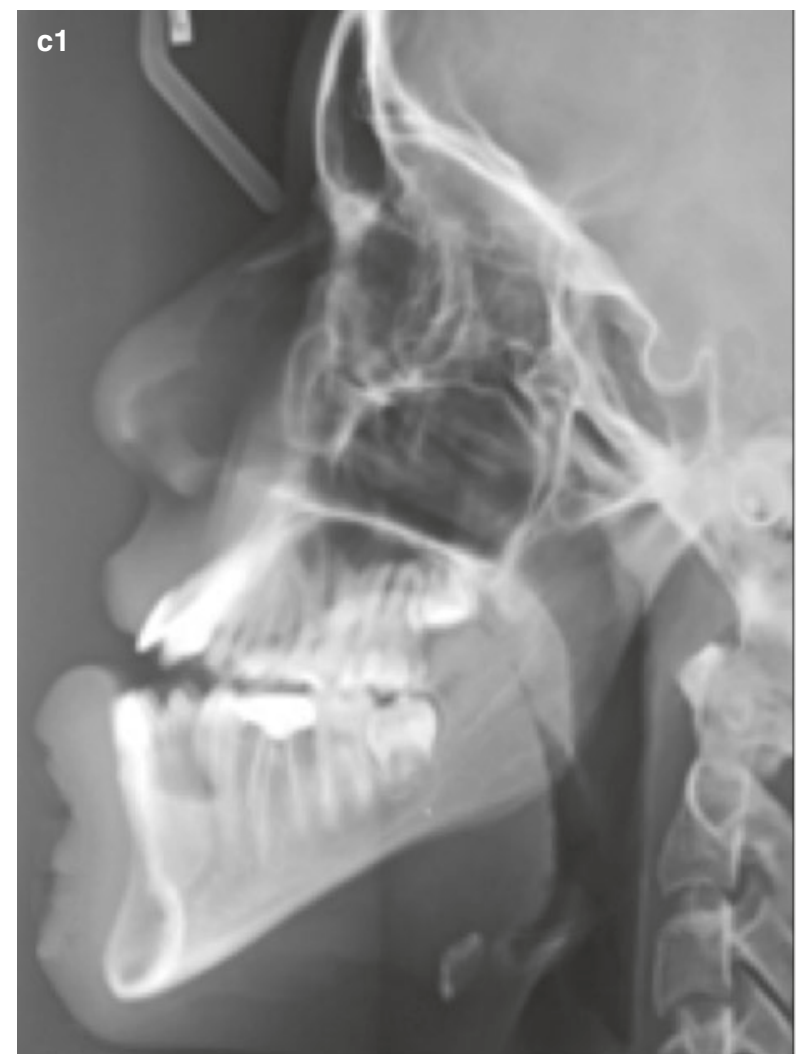

CAssociation of Oral and Maxillofacial Surgeons of India

Fig. 68.20 (continued)

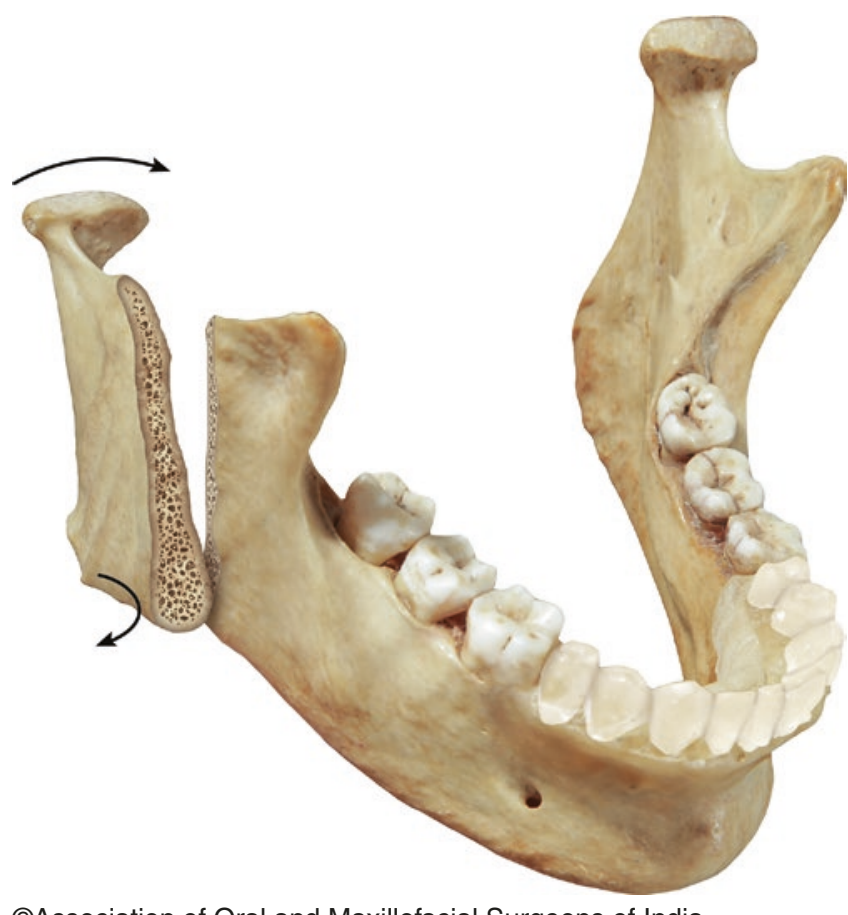

CAssociation of Oral and Maxillofacial Surgeons of India

Fig. 68.21 Displacement of the condyle due to torquing as demonstrated here in a vertical ramus osteotomy, is the most common reason for TMJ problems

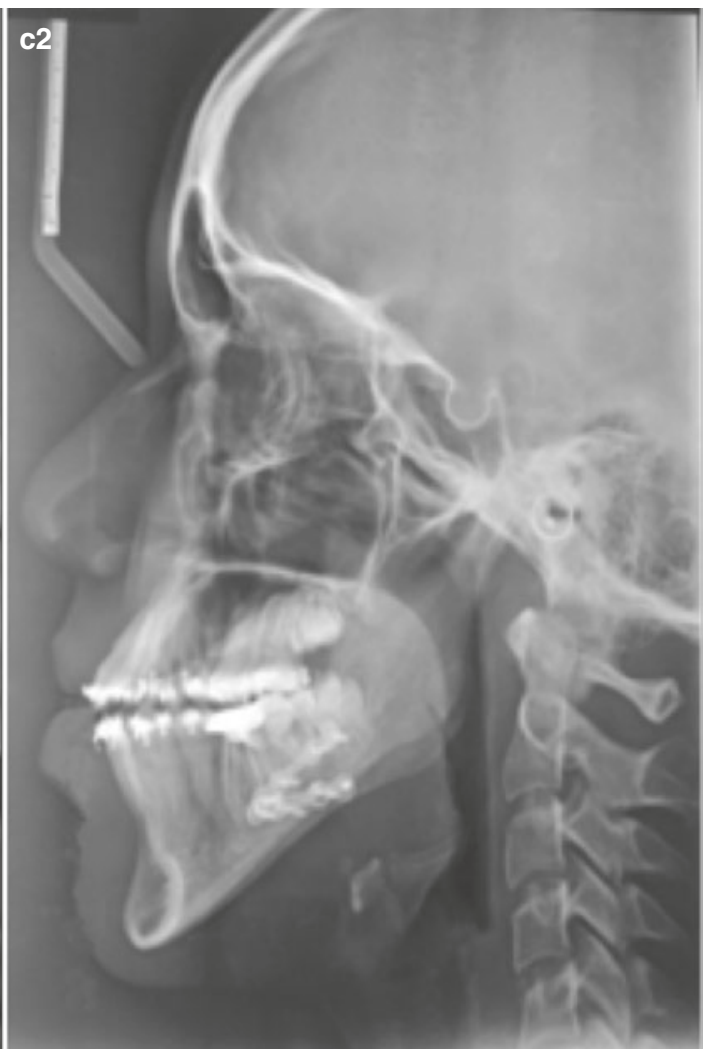
fragments, the coronoid process can be separated using a reciprocating saw. The coronoid process is allowed to retract with the temporal muscle.

An appropriate retractor with a cup at the end can be held hooked to the posterior border, and the soft tissue is held retracted laterally. Care should be taken to orient the cut and also to prevent injury to the soft tissues.

After the osteotomy, the condylar segment is overlapped laterally over the mandible. Medial pterygoid attached to the medial aspect may be stripped in the anterior region of the segment to facilitate tension-free positioning of the condylar segment. The same osteotomy is performed on the opposite side, and intermaxillary fixation is maintained for 6 weeks. Extraoral approach for vertical subsigmoid osteotomy is advocated for large mandibular set back of greater than $10 \mathrm{~mm}[55,56]$.

Over correcting the mandibular set back by $2 \mathrm{~mm}$ to provide compensation for relapse is also recommended [57]. The use of skeletal wire fixation seems to stabilize the initial movement, but does not influence long-term relapse [58].

Ghali and Sikes have reported that IVRO improves TMJ functions and relieves TMJ symptoms more effectively when compared with SSRO, due to the final position of the condyle more anteriorly and inferiorly which 


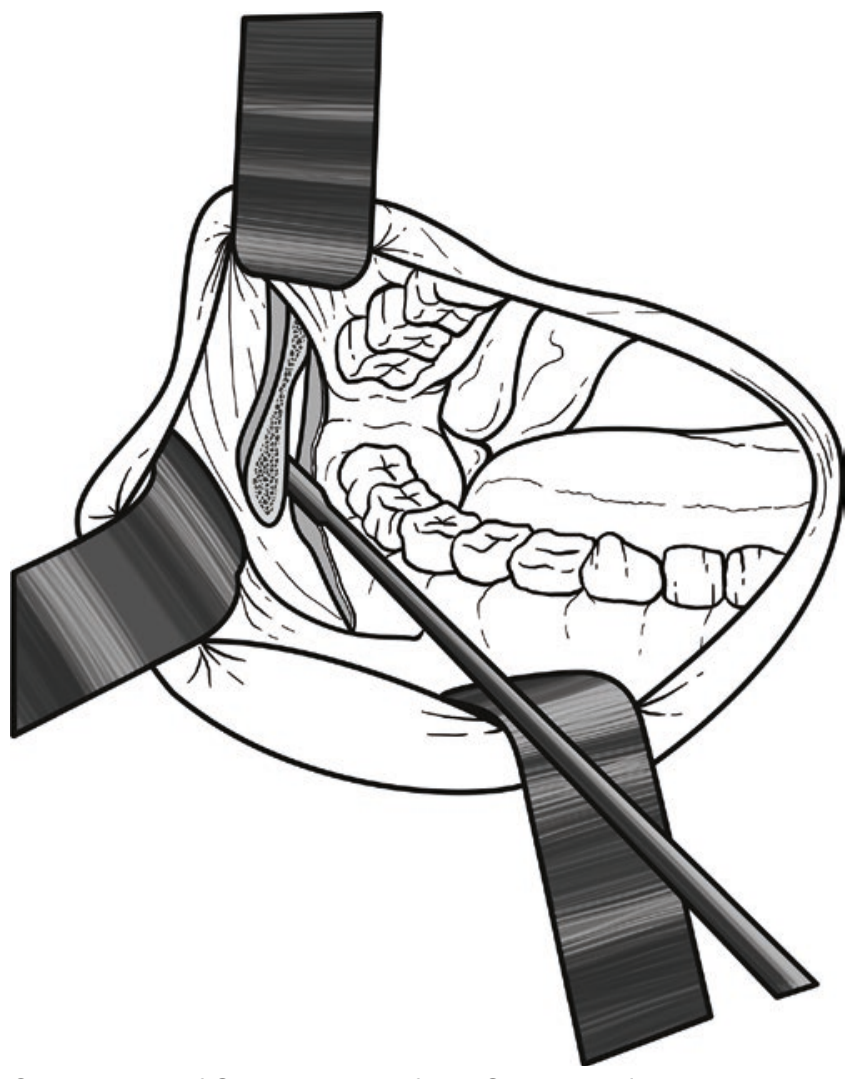

(C)Association of Oral and Maxillofacial Surgeons of India

Fig. 68.22 Diagram for intraoral subsigmoid vertical osteotomy

results in an increased joint space and better disk-condyle relationship [59].

Raúl González-García described endoscopically assisted intraoral vertical ramus (IVRO) and subcondylar (ISCO) osteotomies for the treatment of symmetric mandibular prognathism. He claimed the use of saw and bone chisel under the continuous control of the endoscope provides a safer approach since the osteotomy is controlled during the whole process and provides complete visualization of the osteotomy site [60].

\section{Stabilization, Fixation, and Wound Closure}

Most surgeons use circummandibular or transosseous wires. Rigid internal fixation using plates is rather difficult to place and carries greater risk of injury to the mandibular nerve. Lag screws or mini plates are sometimes used.

Intermaxillary fixation for a period of 6 weeks is advised, if rigid fixation is not used. Wound closure is done as in sagittal split, adhering to the basic principles.

\section{TMJ Considerations}

Radiographically there is an anterior downward and forward movement of the condyle after ramus osteotomy. However, there is a tendency to return to its preoperative position [6163]. Double contouring of the condyle after 6 months was reported which is attributed to condylar remodeling [64]. Remodeling of the glenoid fossa also has been documented [65]. Complications and their management are very much similar to those of sagittal split.

\subsection{Body Osteotomy of Mandible}

This was one of the earlier procedures used for mandibular prognathism. Blair reported a body osteotomy at the premolar level for mandibular prognathism in 1906 [19]. Since the advent of the ramus procedures, body osteotomy has lost its popularity. However, in certain conditions, body osteotomy may have to be resorted to.

\section{Surgical Procedure}

Depending on the site of osteotomy, soft tissue dissection varies. The basic principle is to reflect the buccal mucoperiosteum down to the inferior border taking care not to injure the mental nerve, but at the same time, exposing it.

The next step is to remove the buccal cortical plate from the mental foramen region backward to behind the osteotomy/ostectomy site for release of the neurovascular bundle. The tooth at the osteotomy site is extracted.

Using a fissure bur, the outer cortical plate is marked and a window is cut. Using curettes and chisels, the cancellous bone around the neurovascular bundle is removed. The nerve is released using a nerve hook. Anterior continuation of the inferior alveolar nerve (the incisal branch) is severed. This helps in better retraction of the nerve. Continuation of the mental nerve is preserved. Mucoperiosteum on the lingual aspect is elevated and protected by a periosteal elevator. Osteotomy is completed adhering to the basic principles. The same procedure is repeated on the contralateral side. Body osteotomy at the molar level is almost outdated since the advent of sagittal split osteotomy.

Body osteotomy anterior to the mental foramen can be resorted to in certain specific cases. The main indication of this procedure is lower dentoalveolar protrusion with anterior open bite. "V" osteotomy is done at the first premolar region. This will not reduce the total mandibular length but rotates the anterior segment upward and backward. Maintenance of the arch and occlusion is important. Rigid fixation is mandatory as tendency for relapse is very high due to the pull exerted by the genioglossus and geniohyoid muscles (Fig. 68.23).

Stabilization is achieved by arch bars or by orthodontic means. Fixation using two plates (each plate having a minimum of 4 holes) on each side is advised. 


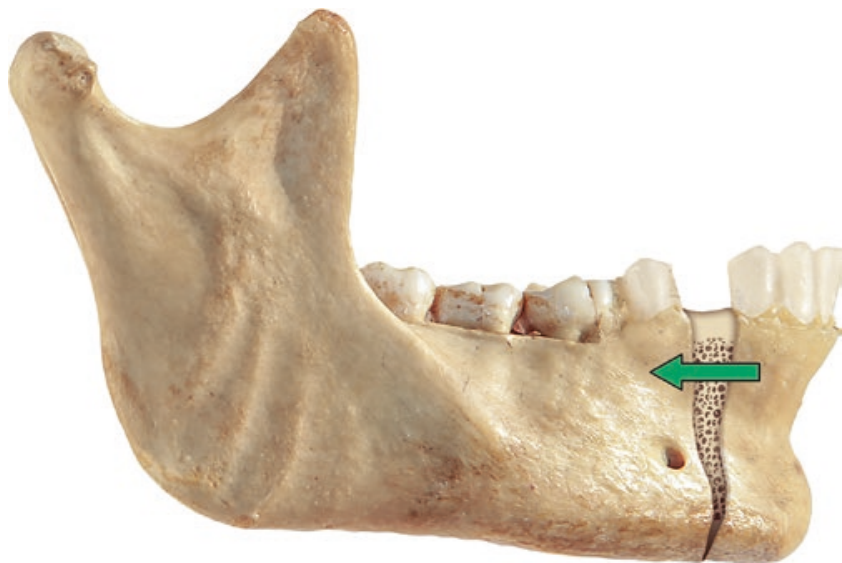

CAssociation of Oral and Maxillofacial Surgeons of India

Fig. 68.23 Body osteotomy at the level of the premolar region. Diagrammatic representation

\subsection{Symphyseal Osteotomy}

Midline osteotomy is used either to narrow or to expand the mandible. Expansion is more difficult than narrowing, due to tissue resistance. Before narrowing the mandible, a space must be created at the symphysis by extracting an anterior tooth (Fig. 68.24). Parasymphyseal step osteotomy approach with a hybrid mode of force application might be the most viable option for true mandibular arch expansion.

\subsection{Lower Anterior Subapical Osteotomy}

Hullihen performed the first ever anterior subapical osteotomy and published it in 1849 [66]. This procedure was done for a girl who had sustained burns and had the anterior segment of the mandible got distracted anteriorly by the traction of the scar resulting in everted lip, protrusion of teeth, and open bite.

Hofer used anterior subapical osteotomy to advance anterior teeth for correction of mandibular dentoalveolar retrusion [67]. Kole used this technique to correct an anterior open bite.

Lower anterior subapical osteotomy is widely used in the following conditions:

1. To retrude the lower anterior dentoalveolar segment; often used in conjunction with subapical osteotomy in bimaxillary protrusion

2. To close minimal anterior open bite

3. To intrude the anterior segment in deep bite deformity

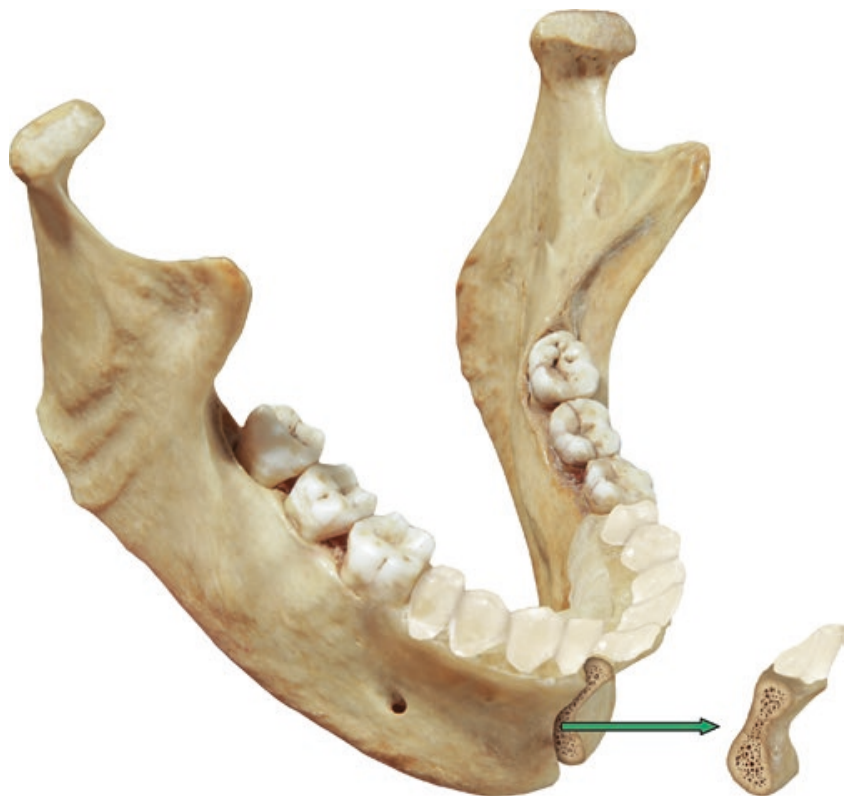

CAssociation of Oral and Maxillofacial Surgeons of India

Fig. 68.24 Midline osteotomy (Diagrammatic representation)

\section{Surgery}

Sulcus incision is made and the mucoperiosteal flap is reflected. Subperiosteal tunneling is done at the lingual aspect of the planned osteotomy site. Extraction of tooth (usually the first premolar) is done, if the intention is to retrude the dentoalveolar segment (Figs. 68.25a, b, c and 68.26a, b, c).

Osteotomy or ostectomy is done as planned. Stabilization and fixation are done in the preplanned position using prefabricated occlusal wafer splint or arch wires. Stabilization is done by using lag screws, position screws, or wires. Semi rigid bone plates are considered superior.

In cases where the anterior segment of the mandible is repositioned superiorly, a gap is created at the osteotomy site (subapically). Autogenous bone grafting is advised to fill this gap.

When the osteotomy is planned behind the mental foramen, the neurovascular bundle may be released from the mandibular canal and protected.

\subsection{Total Subapical Osteotomy Mandible}

Mcintosh in 1974 described total mandibular alveolar osteotomy. In 1942 Hofer [67] described horizontal osteotomy of mandible for horizontal deficiency or excess and asymmetry. 

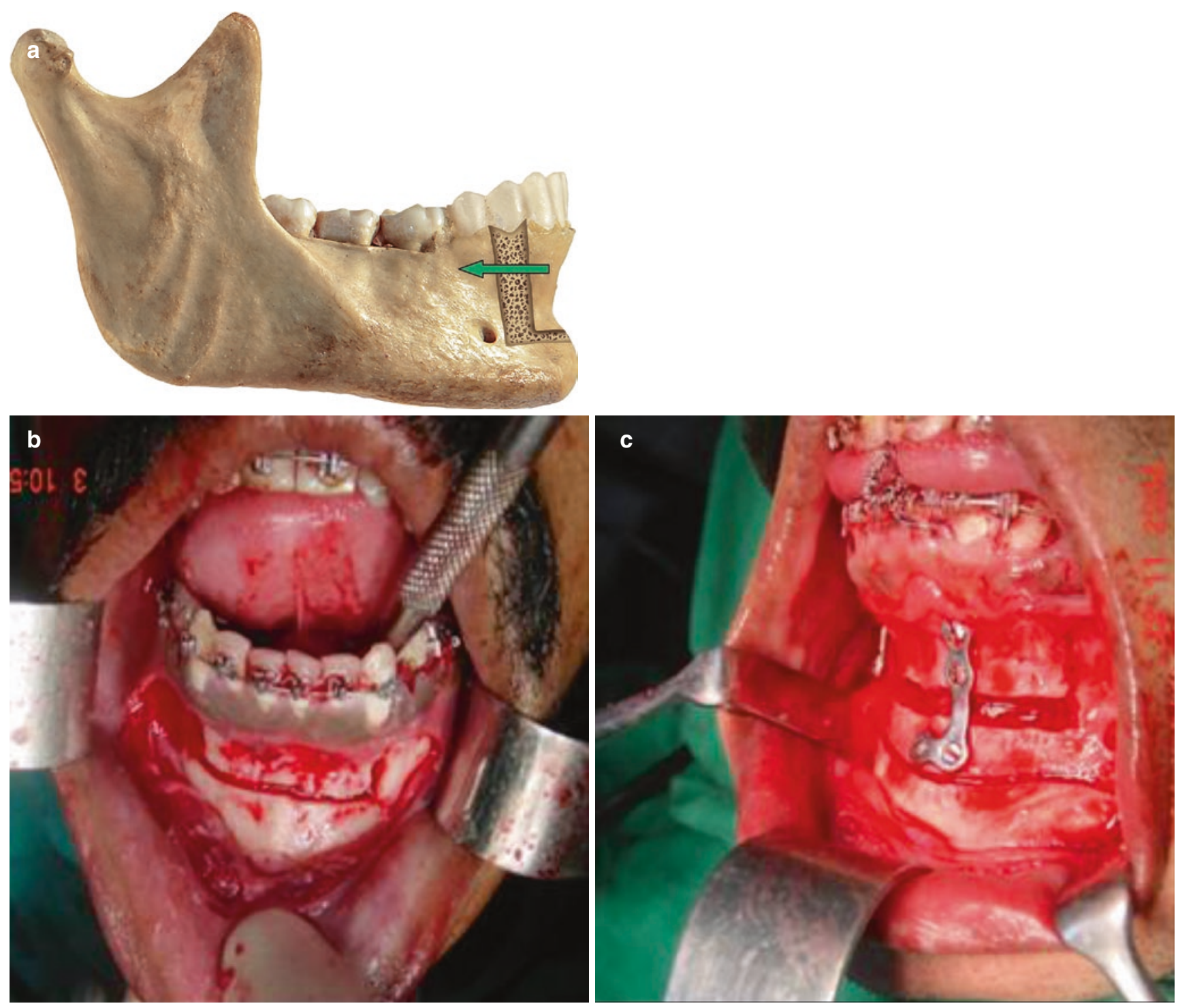

CAssociation of Oral and Maxillofacial Surgeons of India

Fig. 68.25 Lower anterior subapical osteotomy. (a) Diagrammatic representation. (b) Photograph demonstrating the vertical interdental and the horizontal connecting osteotomies. (c) Lower subapical osteotomy can also be combined with genioplasty

Total subapical osteotomy of the mandible is used mailly for the following indications:

1. For repositioning the entire dentoalveolar segment.

2. When the mandibular length and chin position are compatible with the maxilla and its position, but the deformity is mainly in the dentoalveolar part.

Adequate bone should be present below the apices of the roots.

\section{Surgery (Fig. 68.27a, b, c)}

Mucoperiosteal flap is reflected. The neurovascular bundle is released as described earlier (under "Body Osteotomy of Mandible"). Osteotomy is started behind the most posterior teeth. The cut is made using reciprocating saw or bur. Care should be taken not to damage the lingual tissues. Osteotomy is continued anteriorly, without injuring the released neurovascular bundle. About $4 \mathrm{~mm}$ of bone should be left below the apices of the teeth to ensure proper blood supply. The dentoalveolar segment is freed and mobilized. Preplanned 


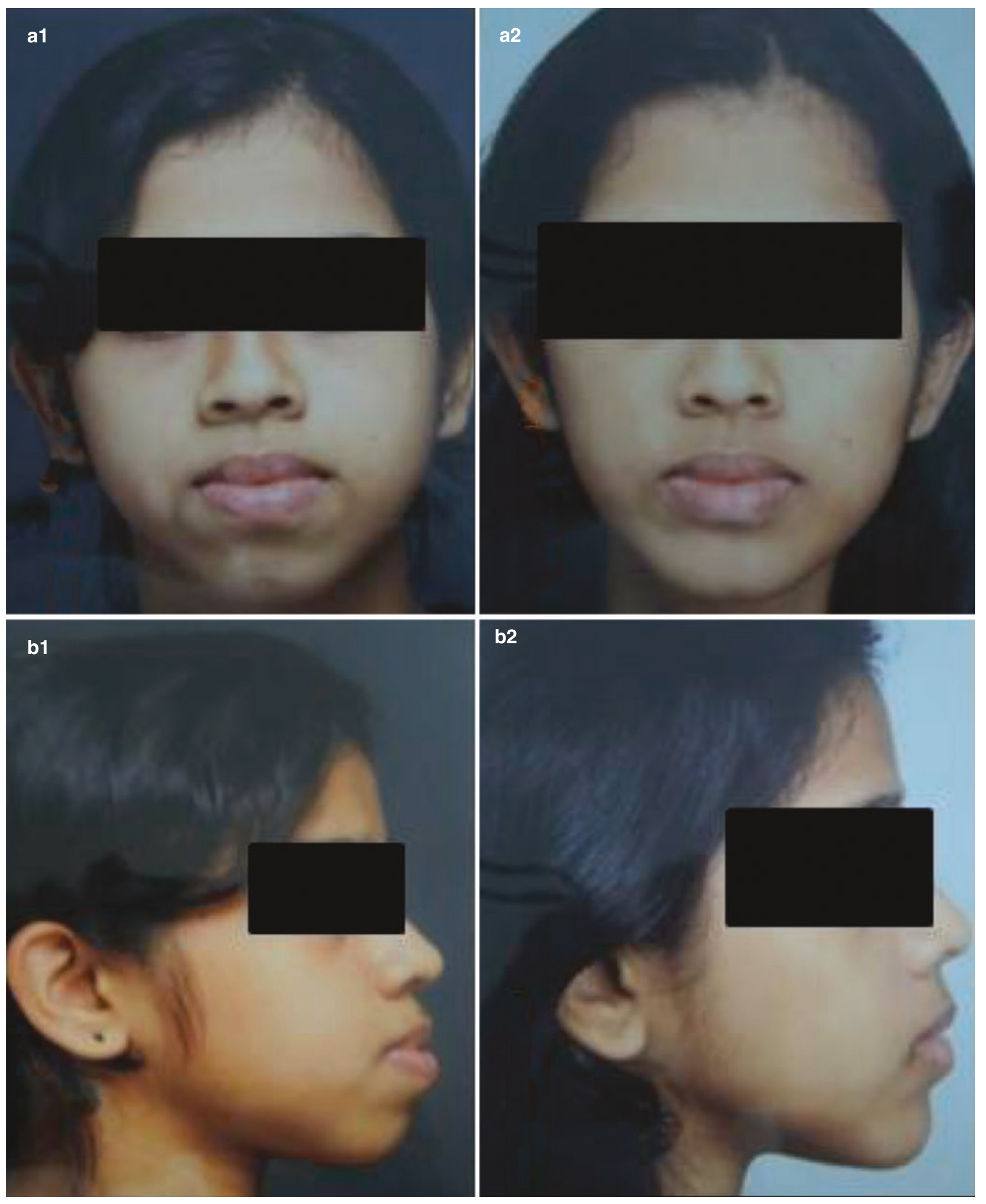

Fig. 68.26 Protrusion anterior dentoalveolar segment of mandible treated by lower anterior subapical osteotomy. (a1, b1) Preoperative pictures. (a2, b2) Postoperative pictures. (c1) Preoperative lateral cephalogram. (c2) Postoperative lateral cephalogram 


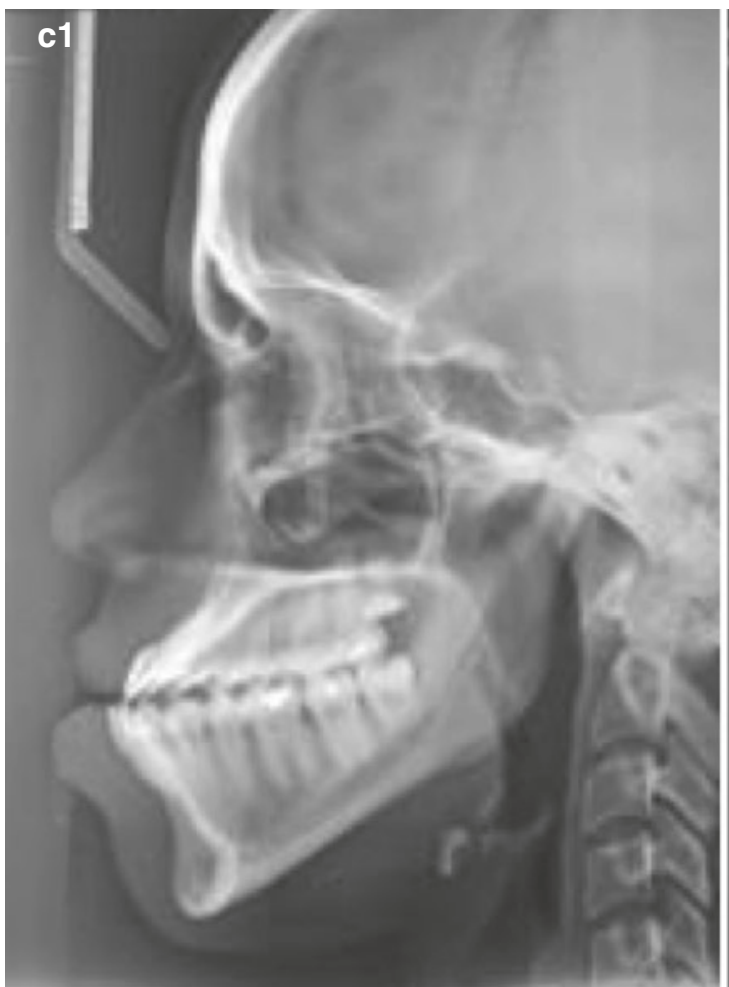

CAssociation of Oral and Maxillofacial Surgeons of India

Fig. 68.26 (continued)

occlusion is established. Maxillomandibular fixation is aided by wafer splint. The neurovascular bundle is repositioned and secured in position using struts of bone [68].

Stabilization is done using rigid internal fixation. Postoperative sequelae are usually marked by edema which gets resolved in about 2 weeks. Sensory disturbances, though present, usually recover with time. Injury to the neurovascular bundle may cause permanent anesthesia.

Complications are usually rare. The importance of proper blood supply through the lingual pedicle is of utmost importance. This is mainly through the mylohyoid, genioglossus, and geniohyoid muscle attachments.

\subsection{Posterior Subapical Osteotomy Mandible (Fig. 68.28)}

The basic plan of the surgery is not very different from that of total subapical osteotomy. The incision is limited to the posterior area. The decompression of the neurovascular bundle is done, and the osteotomy is performed as described earlier.

The main indications are to shift the dentoalveolar segment in question to the required direction in all three dimensions of space, i.e., antero-posterior, vertical, or horizontal.

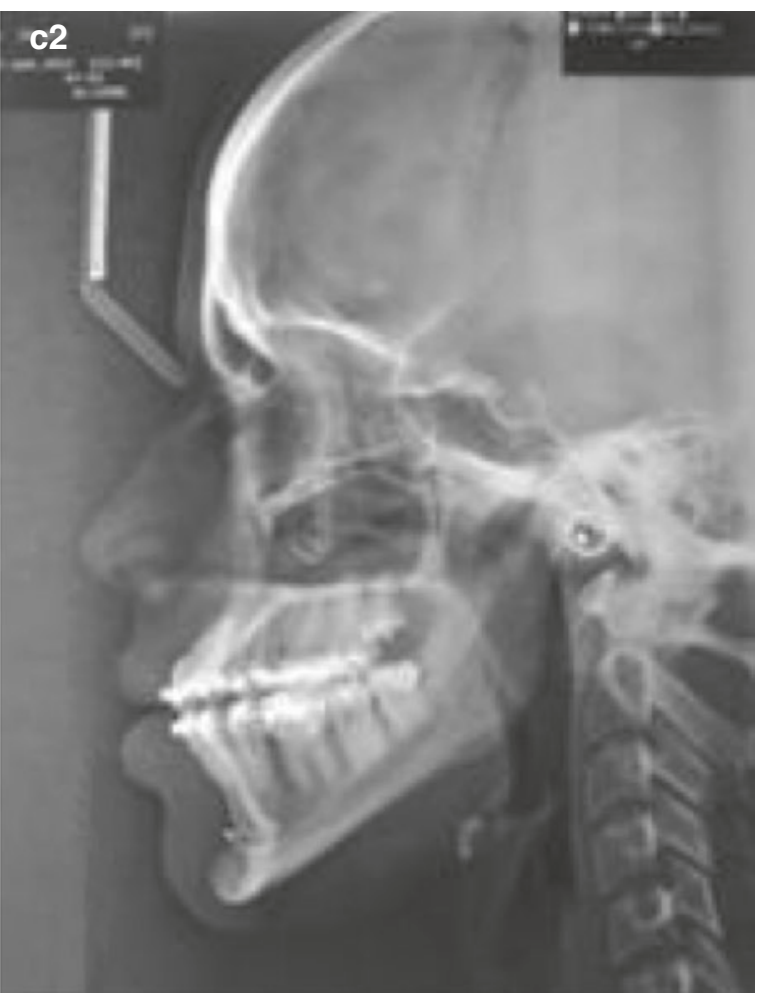

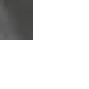




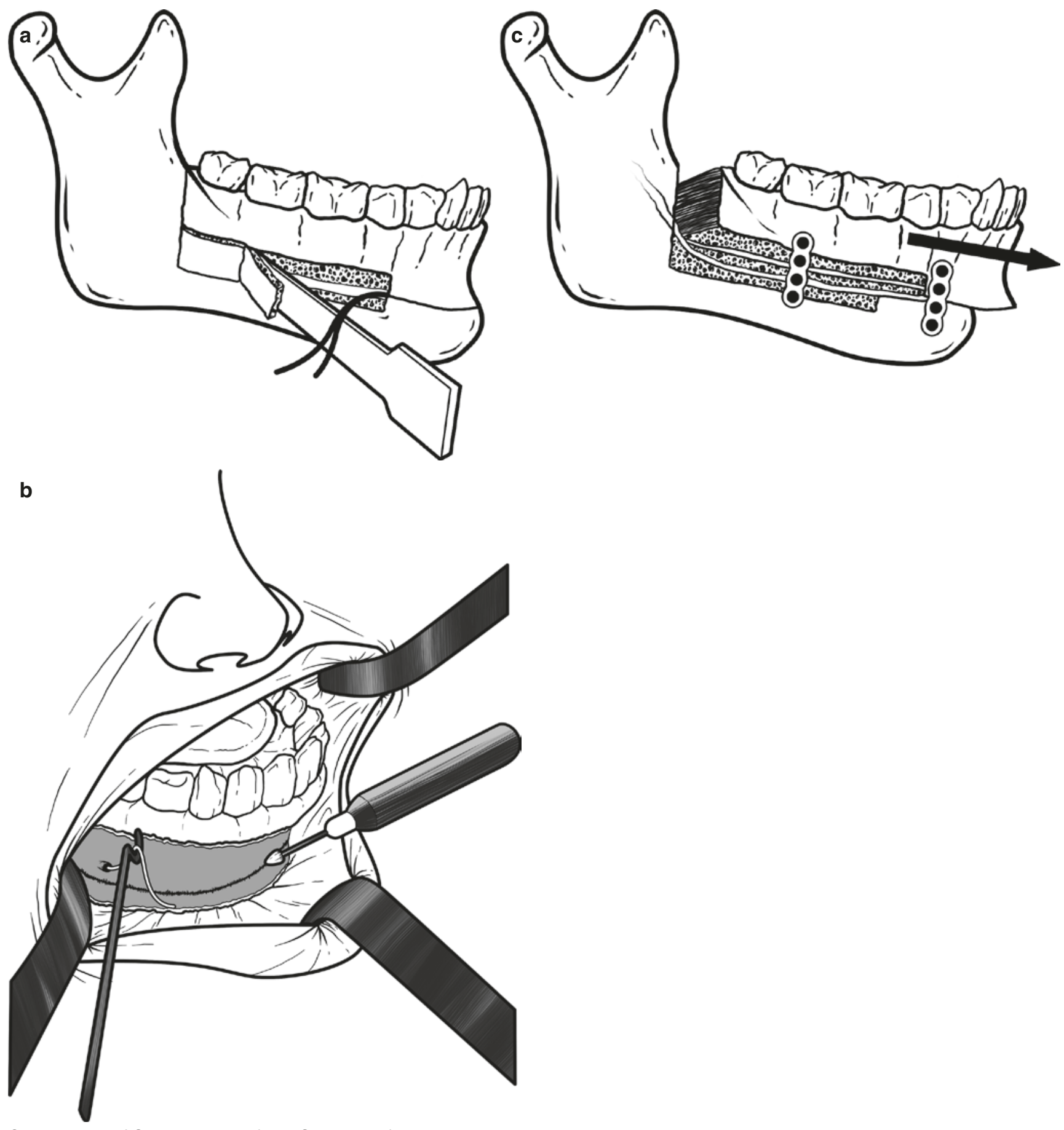

CAssociation of Oral and Maxillofacial Surgeons of India

Fig. 68.27 Total subapical osteotomy. (a) Neurovascular bundle is released. (b) Osteotomy is done using bur or saw. (c) The dentoalveolar segment is positioned and fixed rigidly.

and necrosis may occur [70, 71]. The degree of bone resorption and necrosis is indirectly proportional to the amount of pedicle attached to the segment [72].

For vertical reduction, another horizontal cut is made below the original cut, and the measured segment of bone between the two cuts is removed. It is not advisable to cut off the bone from the inferior border as this can imperil the normal contour of the chin. Unilateral vertical reduction/augmentation can be done for correction of asymmetry, since the chin can be moved in all three dimensions (Fig. 68.31a, b).

Increase in the height of the chin can be achieved by bone grafting (preferably autogenous) and rigid internal fixation 
using plates. Unilateral height increase can be done in asymmetry. However, high morbidity is associated with bone graft and alloplastic materials, such as recurrence, infection, and resorption [73]. Chin can be augmented (augmentation genioplasty) (Fig. 68.30a-c) by bringing the cut inferior segment anteriorly and fixing it by rigid fixation. For major advancement, stepwise augmentation, slicing the inferior border into more than one horizontal segment is advocated (Figs. 68.32 and 68.33a, b, c) (Also refer Fig. 78.42).

Retropositioning of the chin can also be done, but the soft tissue adaptation following posterior positioning of the chin is

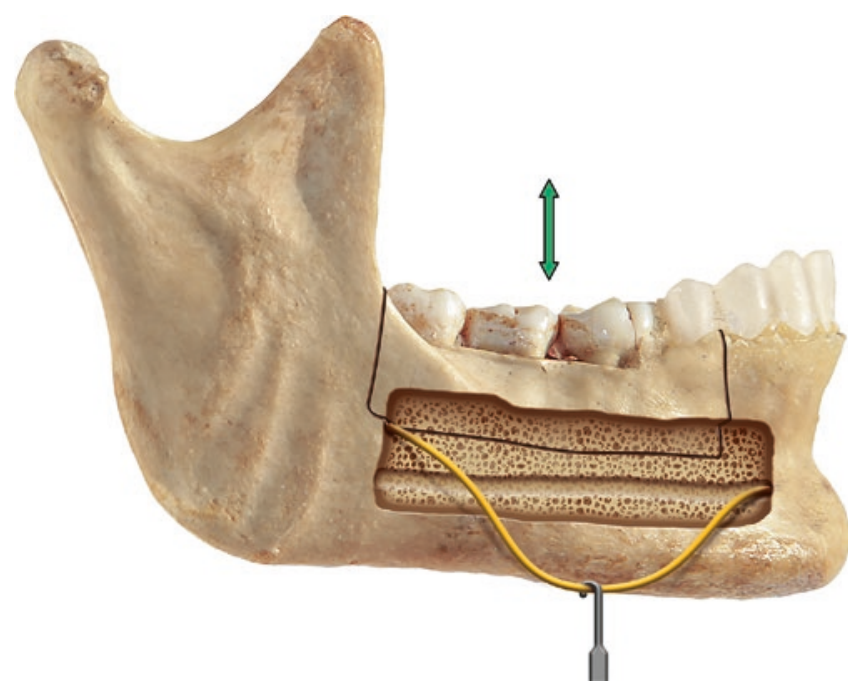

CAssociation of Oral and Maxillofacial Surgeons of India

Fig. 68.28 Posterior subapical osteotomy not $100 \%$. While positioning the inferior border posteriorly, the labiomental fold may get compromised (Fig. 68.34a, b).

Genioplasty can be used for widening and narrowing the chin in the horizontal direction. In mild mandibular asymmetry, the midpoint of the chin may be off the facial midline. By horizontal repositioning of the inferior border, the midpoint of the chin can be brought to the midline of the face, and the mandibular asymmetry can be camouflaged (Fig. 68.35).

Following surgery, the wound is closed adhering to the basic principles. Like in other osteotomies, 3-6 months are necessary for the lip to adapt to the new position and resume normal function. Complications are rare with this procedure. Wound dehiscence occurs in some cases. Meticulous irrigation and aseptic measures can reduce the chances of infection. Sensory loss for a period may be noticed due to traction on the mental nerve. Often sensation is regained within 3-6 months. Rigid fixation technique has reduced the chances shifting of position of the moved segment. Though the reported relapse rates vary in genioplasty, most authors agree that relapse occurs within the first year $[38,70]$.

\subsection{Extended Genioplasty/Mandibular Basal Osteotomy}

Mandibular basal osteotomy is an innovative predictable technique for correction of deficiency, excess, and/or asymmetry of the inferior mandibular border, decreasing morbidity, and many other complications of traditional bone grafts and alloplastic techniques [74].
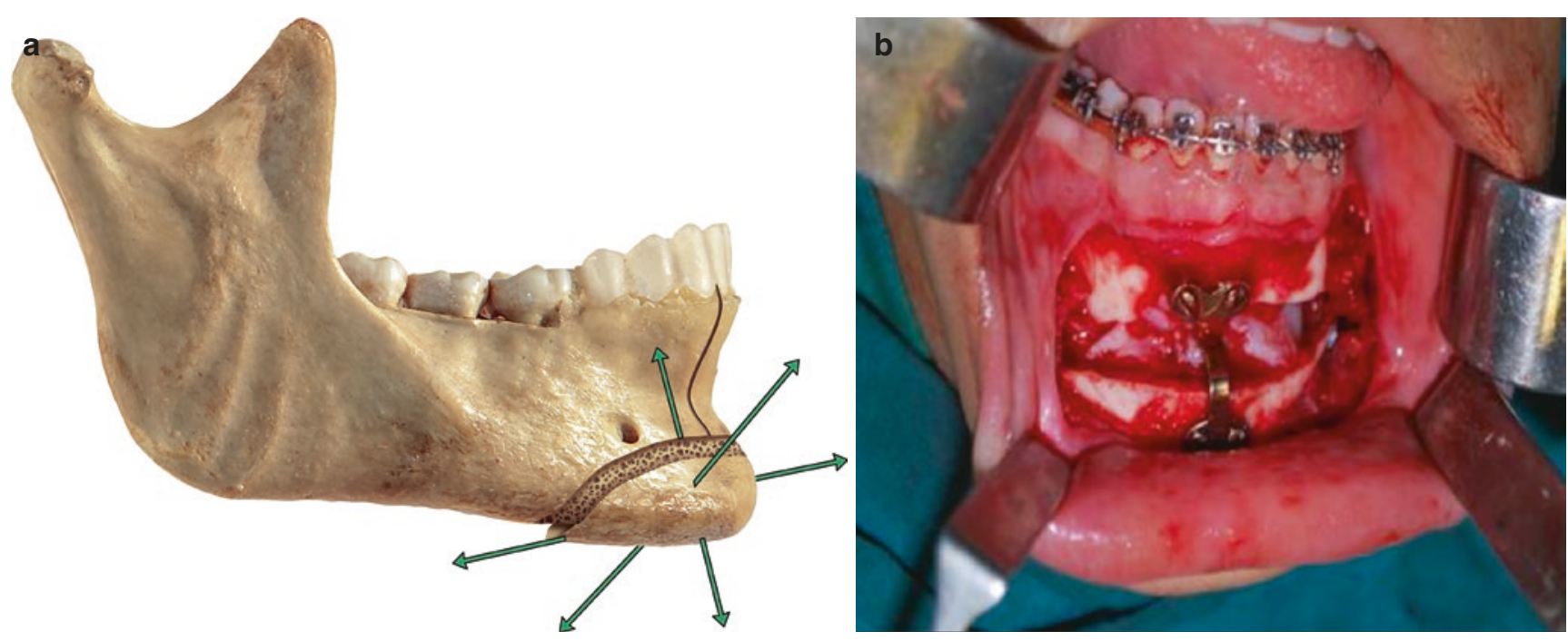

CAssociation of Oral and Maxillofacial Surgeons of India

Fig. 68.29 (a) Osteotomized chin can be moved in all the three dimensions. (b) Advancement genioplasty 
Fig. 68.30 Case of augmentation genioplasty. (a1, b1) Preoperative pictures. (a2, b2) Postoperative pictures. (c1) Preop lateral cephalogram. (c2) Post op lateral cephalogram
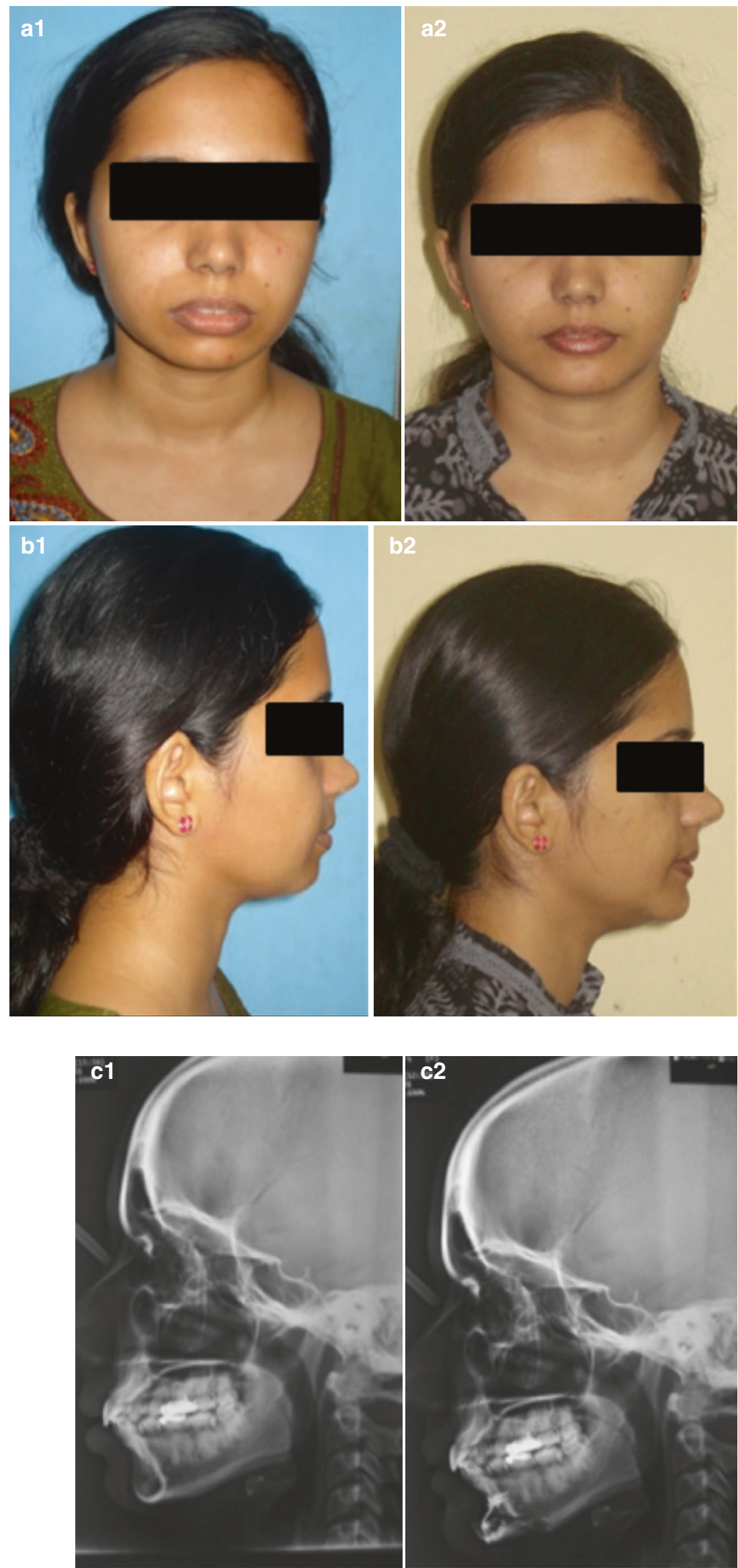

CAssociation of Oral and Maxillofacial Surgeons of India
Fig. 68.30 (continued) 

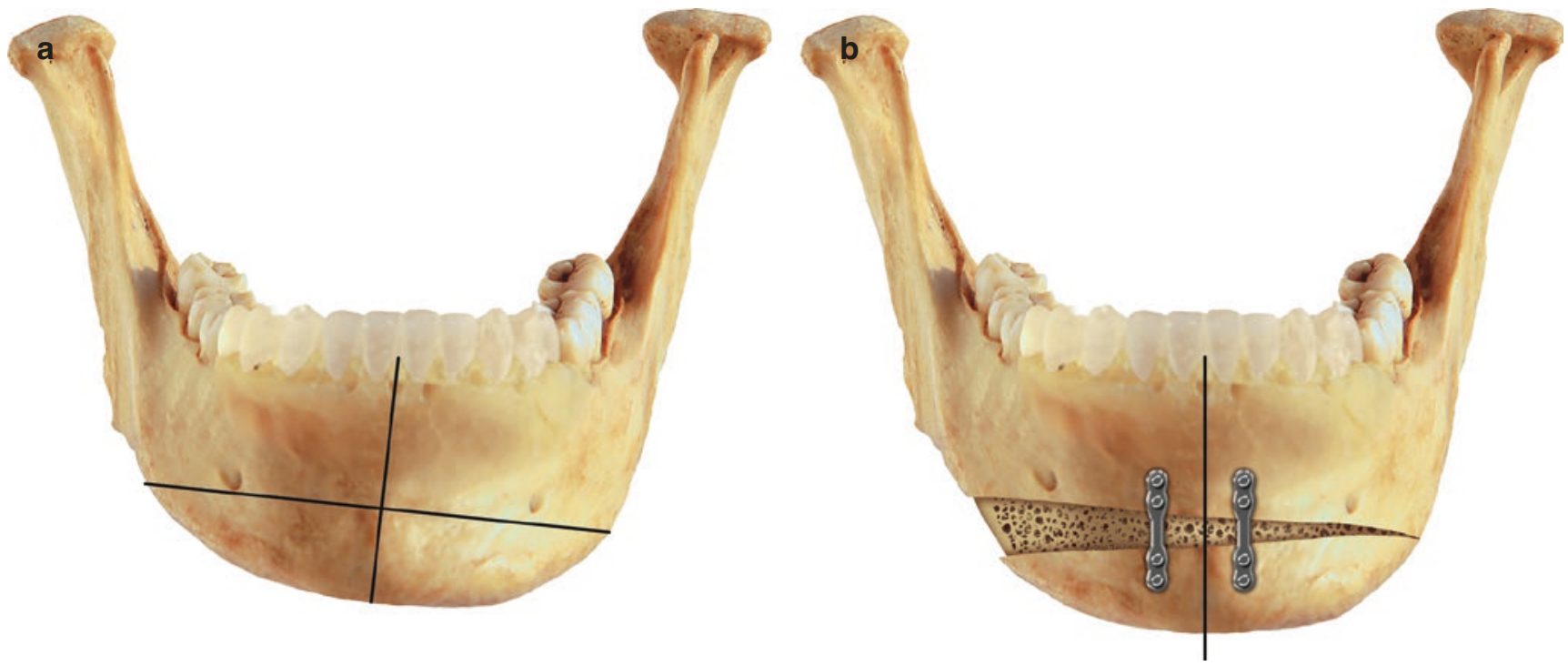

CAssociation of Oral and Maxillofacial Surgeons of India

Fig. 68.31 Mild facial asymmetry can be corrected by bone grafting on one side, after osteotomy. (a) Pre-operative assessment and (b) treatment (osteotomy design)

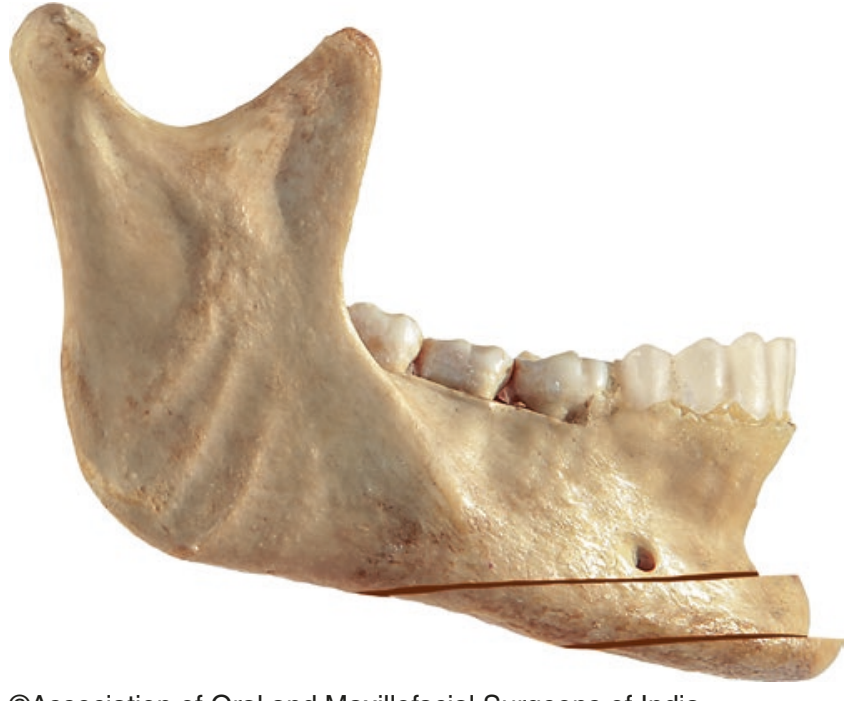

CAssociation of Oral and Maxillofacial Surgeons of India

Fig. 68.32 Major advancement of the chin can be effected by a double sliding genioplasty, which is a step osteotomy of the lower border

In extended genioplasty dissection and exposure of the chin, mental nerve and body of the mandible is recommended by a degloving incision. With complete dissection and mobilization of nerves, an extended osteotomy to the antegonial angle may be carried out (Fig. 68.36a, b). The basal osteotomy below the inferior alveolar canal ensures proper proportionality between the advanced segment and the posterior mandible [75]. By laterally sliding the lower border (extended lateral sliding genioplasty), facial asymmetry can be corrected. This procedure can be used for minimal to moderate hemifacial microsomia and facial deformity resulting from unilateral ankylosis of the temporomandibular joint [76] (Fig. 68.37a, b).

\subsection{Distraction Osteogenesis}

Distraction osteogenesis is a recent introduction into the field of orthognathic surgery. This technique has revolutionized the possibilities of orthognathic surgery. It was Ilizarov, a Russian orthopedic surgeon, who popularized this technique. The first team to report gradual distraction of human mandible was McCarthy et al. in 1992 [77]. As bone has got regenerative capabilities, it is possible to create new bone and lengthen the bone in a cut segment by slowly distracting it. The technique is very useful in the management of deficiency of bone in the maxillofacial region as this is an excellent method to increase bone quantity. The spectrum of indications for distraction is widening and innovations are coming up in the field rapidly. During distraction certain important principles are to be followed.

It is advisable to complete the osteotomy and mobilize the segment as far as possible and then put back the segment to its original position and distract it gradually. During distraction directional stability should be ensured, in order to counteract the pull of the soft tissue and the muscles [78]. A new terminology "distraction histogenesis" has come into vogue as not only the bone but the surrounding tissues also get lengthened. Geniohyoid muscle can be lengthened to a maximum of $20 \%$ of its resting length [79]. It is possible to distract the inferior alveolar nerve as well [80]. It is important that the distracted tissue is attached to vital tissue to maintain 

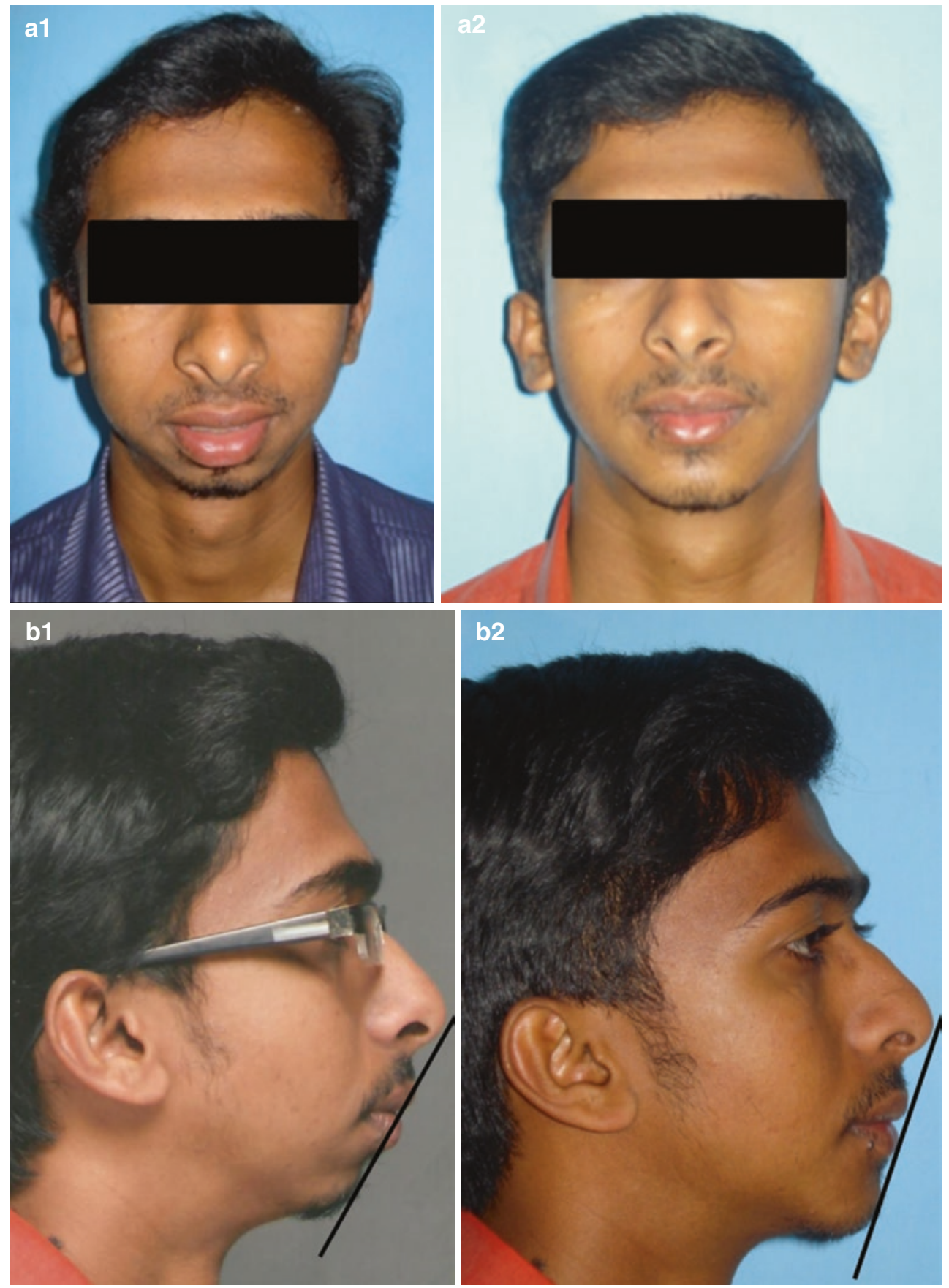

Fig. 68.33 Case of retruded chin corrected by double sliding advancement genioplasty. (a1, b1) Preoperative pictures. (a2, b2) Postoperative pictures. (c1) Preoperative lateral cephalogram. (c2) Postoperative lateral cephalogram

perfusion. Periosteum is rich in osteogenitor cells, and for callus distraction and bone lengthening, the periosteum should be intact, and hence it should be preserved [48].

After osteotomy a latency period of 4-7 days is advised to provide time for the soft tissue to heal. However other factors like age, stability of fixation, type of operative procedure that affects the formation process during the initial stages of distraction, etc. are to be considered before deciding on the latency period [81]. Certain other studies did not show any difference between no latency period and a latency period $[82,83]$.

Four stages are recognized in distraction osteogenesis(a) fibrovascular hematoma formation, (b) formation of collagen fibers parallel to distraction vector, (c) bone formation and remodeling of new bone, and (d) formation of solid compact bone. In fast distraction collagen, fibers may lose contact, and bone formation may not take place. In slow 

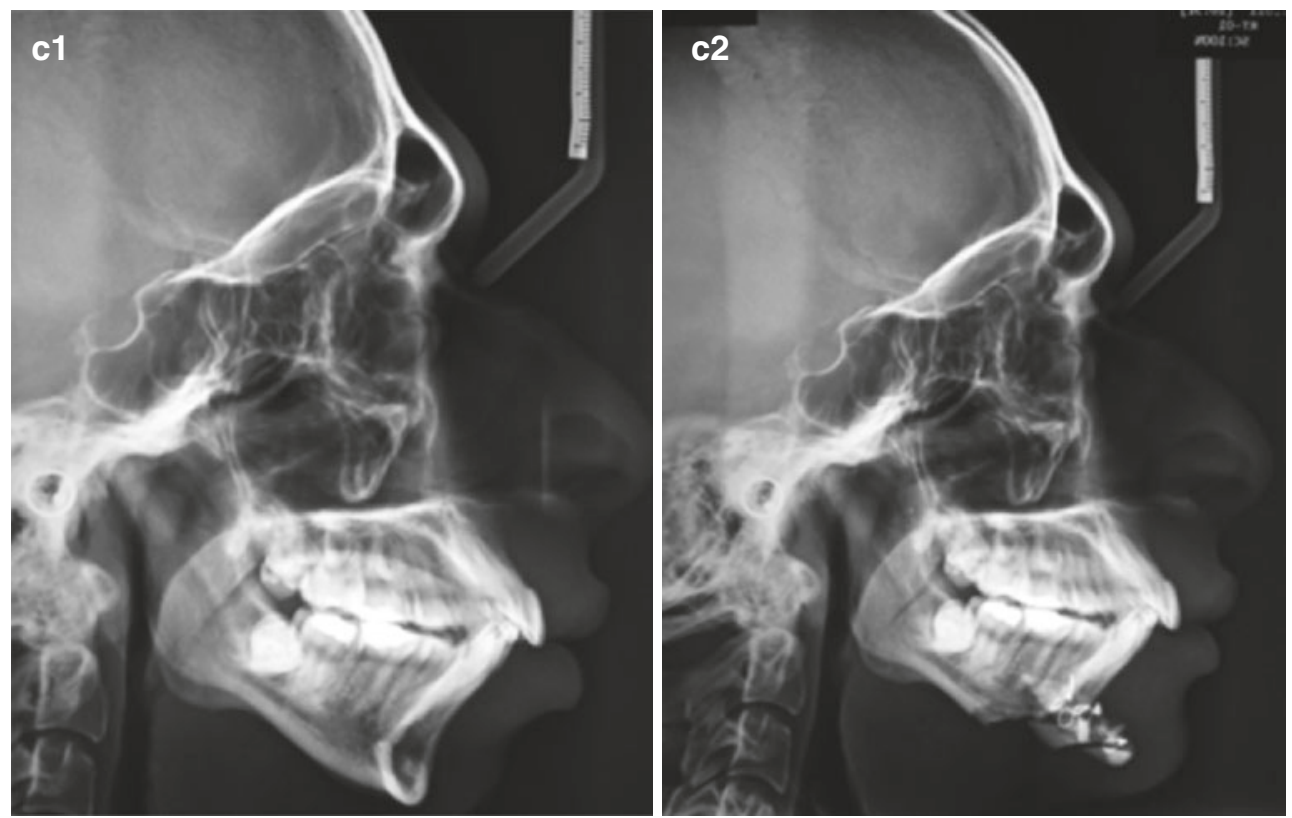

CAssociation of Oral and Maxillofacial Surgeons of India

Fig. 68.33 (continued)
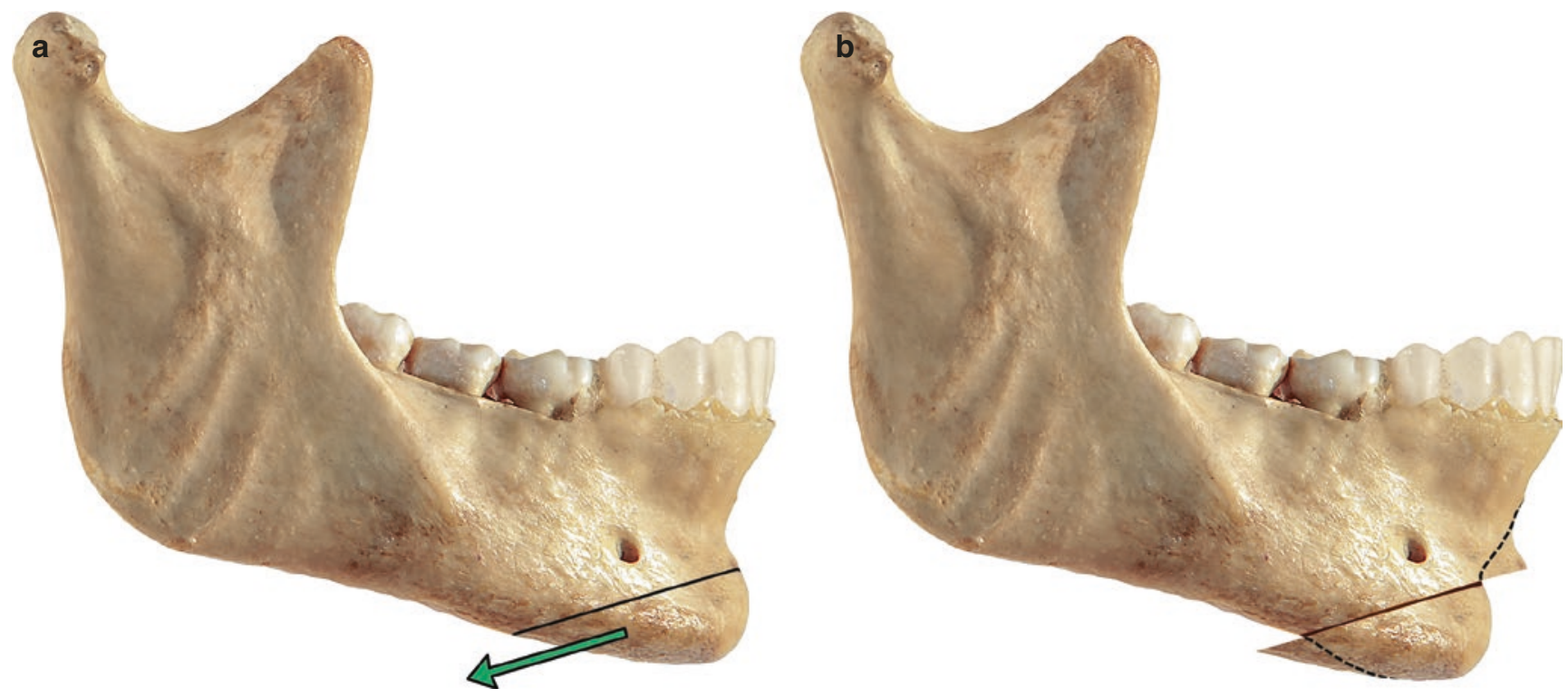

CAssociation of Oral and Maxillofacial Surgeons of India

Fig. 68.34 Reduction of the chin can also be achieved. However, sharp margins are to be trimmed off. (a) Pre-operative planning and (b) treatment (osteotomy design) 
distraction, consolidation of bone may occur earlier [84]. Karp et al. demonstrated that intramembranous ossification is what occurs predominantly [85]. Distraction of $1 \mathrm{~mm}$ per day is the widely accepted rate [86]. Direct current electrical stimulation may be useful in activation and consolidation

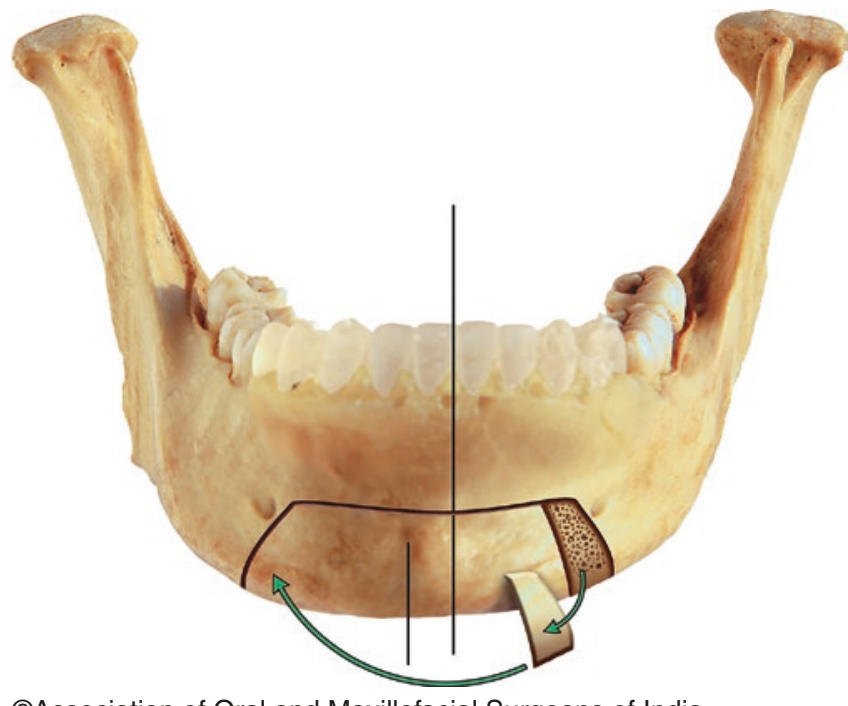

CAssociation of Oral and Maxillofacial Surgeons of India

Fig. 68.35 Osteotomy plan for mild facial asymmetry pertaining to the chin period [87-89]. Insufficient distraction and defective vectors can compromise the final result. These complications can be, to some extent, managed by manipulating the regenerate bone by the application of orthodontic traction [79, 90-92]. OW and Cheung reported a lower incidence of persistent IAN disturbance (3\%) after MDO compared with BSSO, of which the incidence was $28 \%$ [93]. In terms of skeletal stability in small to moderate advancements, there is no significant difference between BSSO and DO. DO requires a second surgery for removal of the distractor, which goes in favor of BSSO [94].

Distraction osteogenesis has got an important role in managing sleep apnea, in cases like micrognathia, Pierre Robin syndrome, hemifacial microsomia, Treacher Collins syndrome, etc. $[4,95]$. Due to its complex nature, it is rather difficult to treat unilateral craniofacial microsomia, in growing children. Maxilla, zygoma, mandible, external and middle ear, facial and trigeminal nerves, muscles of mastication, and overlying soft tissues are the structures of the first and second arch which are involved [96] (Refer Chap. 78 on Hemifacial microsomia and Treacher Collins syndrome).

In severe cases, in neonatals, tracheostomy may become necessary. Mandibular distraction is an effective method in resolving upper airway obstruction and decannulation of tracheostomy [97-99]. Rachmiel A. et al. have reported an increase of mandibular volume by $28.4 \%$, increase of upper airway volume
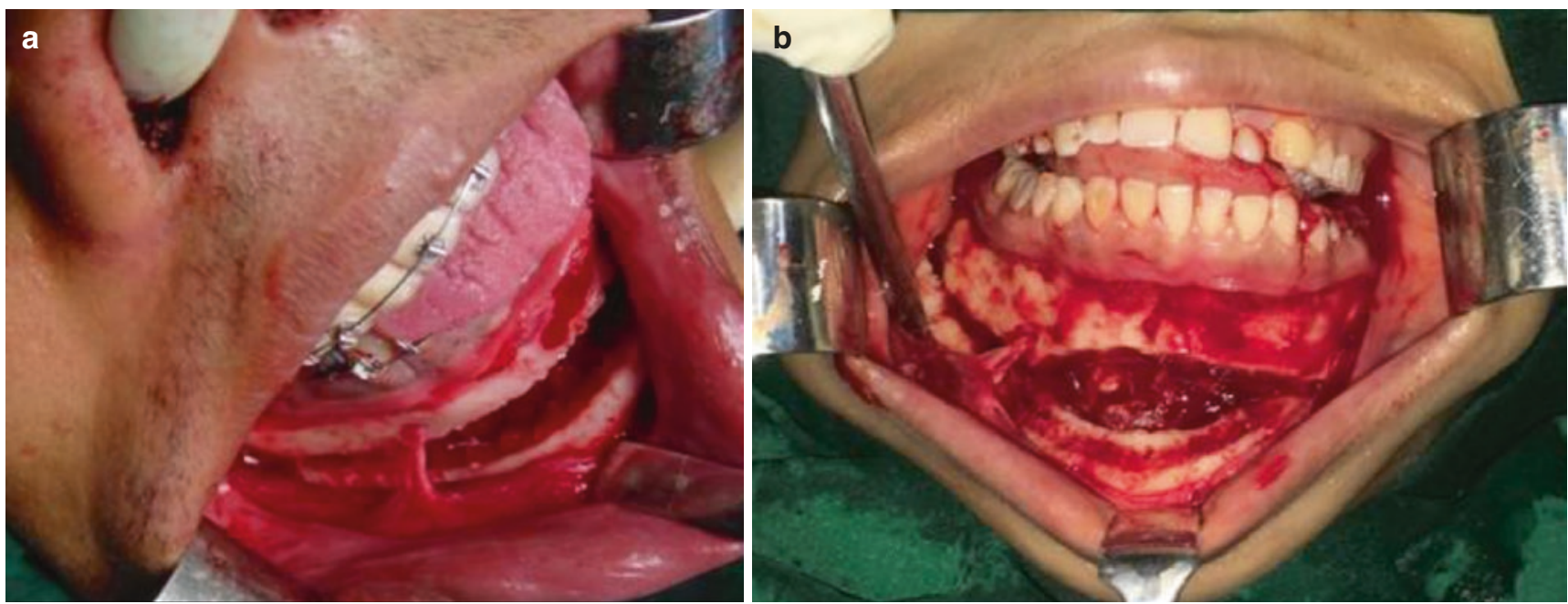

CAssociation of Oral and Maxillofacial Surgeons of India

Fig. 68.36 After making a degloving incision an extended genioplasty may be done. it is possible to preserve the mental nerve. (a) Oblique view and (b) frontal view 

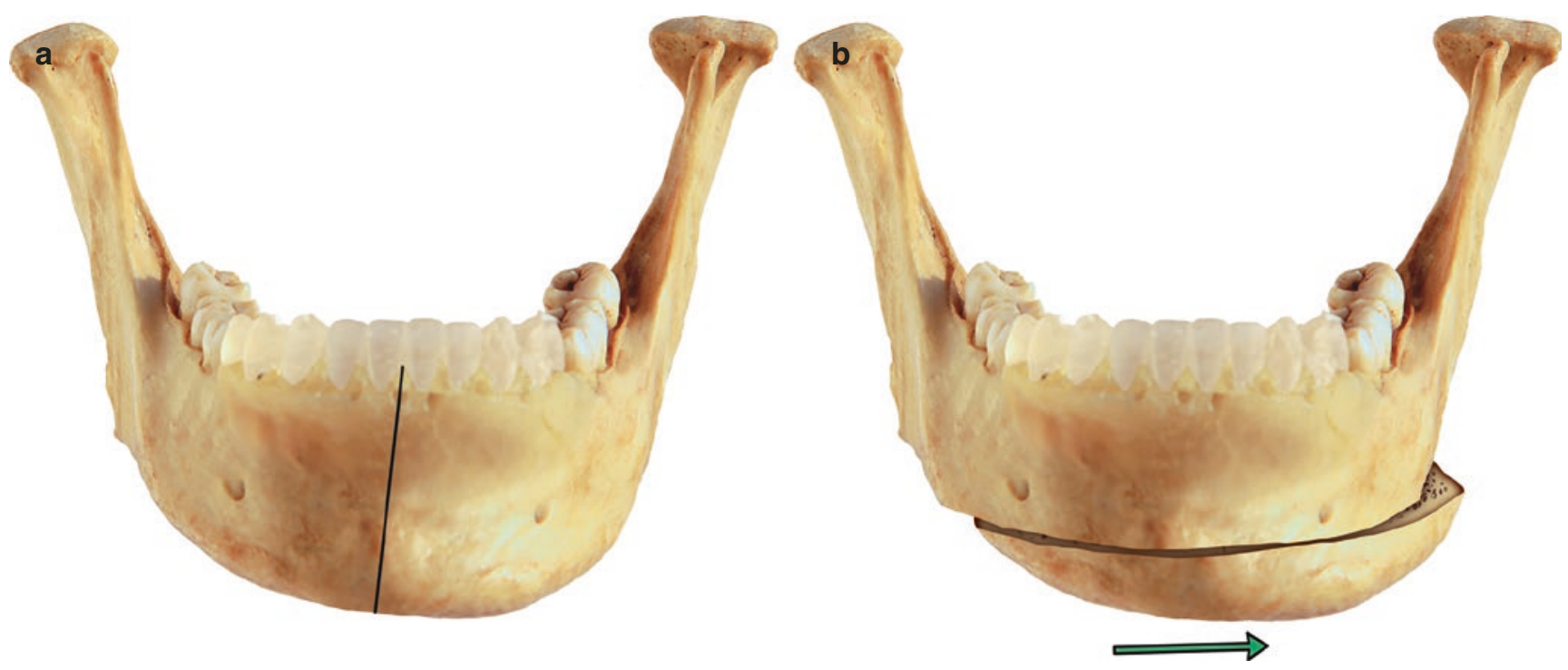

CAssociation of Oral and Maxillofacial Surgeons of India

Fig. 68.37 Major asymmetry of the mandible can be corrected to a great extent by extended lateral sliding genioplasty. (a) Pre-operative plan and (b) treatment (osteotomy design)

by $71.92 \%$, and increase in oxygen saturation. This study was conducted in children between 13 months and 7 years of age [25] (refer Chap. 87 on distraction osteogenesis).

In severely hypoplastic mandible multi-stage correction starting from young age may be considered for functional and psychological reasons. Less severe cases may be taken up for single stage correction after the permanent dentition is erupted [100].

\subsection{Conclusion}

Mandible is a horse shoe-shaped bone hinged to the skull and performs the major function, chewing, and forms the lower part of the mouth which houses the tongue and other musculature. All the muscles of mastication and many other muscles of facial expression are attached to the mandible. Hence mandible is an important structure in both function and aesthetics. Different osteotomies of mandible can move the jaw in almost all the three directions and change the size and shape of the jaw and face to achieve better function and aesthetics. This chapter is intended to elucidate various osteotomy techniques on the mandible.

Disclosure Authors have no financial conflicts to disclose.

\subsection{Case Scenarios}

\section{Case 1 (Fig. 68.38a, b, c)}

Patient aged 22 years, female, reported with complaint of facial deformity with a history of fall when she was about 8 years old. No deformity was noticed, and no treatment was taken at that time, and as she grew up, she started developing deviation of the face.

On examination she had facial asymmetry with deviation of the jaw to left side. She had class II occlusion and deficient chin. Radiographs revealed under developed and deformed condyle on the left side. The mandible was shifted to the left side due to underdevelopment of the mandible on left side (Fig. 68.38a1, b1, c1).

Treatment: Pre-surgical orthodontic treatment with sagittal split osteotomy and extended lateral sliding genioplasty with rib bone grafting on right side.

Postoperative pictures after 1 year (Fig. 68.38a2, b2, c2).

\section{Case 2 (Fig. 68.19a, b, c)}

Patient aged 19 years reported with complaint of protruded teeth and facial deviation with no relevant history.

On examination, she had vertical maxillary excess with mandibular prognathism. Other clinical findings included incompetent lips, convex facial profile, acute nasolabial angle, and facial asymmetry with deviation of chin toward right side. Radiographs revealed vertical and anterioposterior maxillary excess with mandibular prognathism and deficient chin.

Preoperative pictures (Fig. 68.19a1, b1, c1)

Treatment plan: Pre-surgical othodontic treatment followed by surgery.

Surgery: LeFort 1, anterior maxillary osteotomy, bilateral sagittal split osteotomy, and genioplasty were done for the patient under general anesthesia.

Postoperative pictures after 1 year (Fig. 68.19a2, b2, c2) 

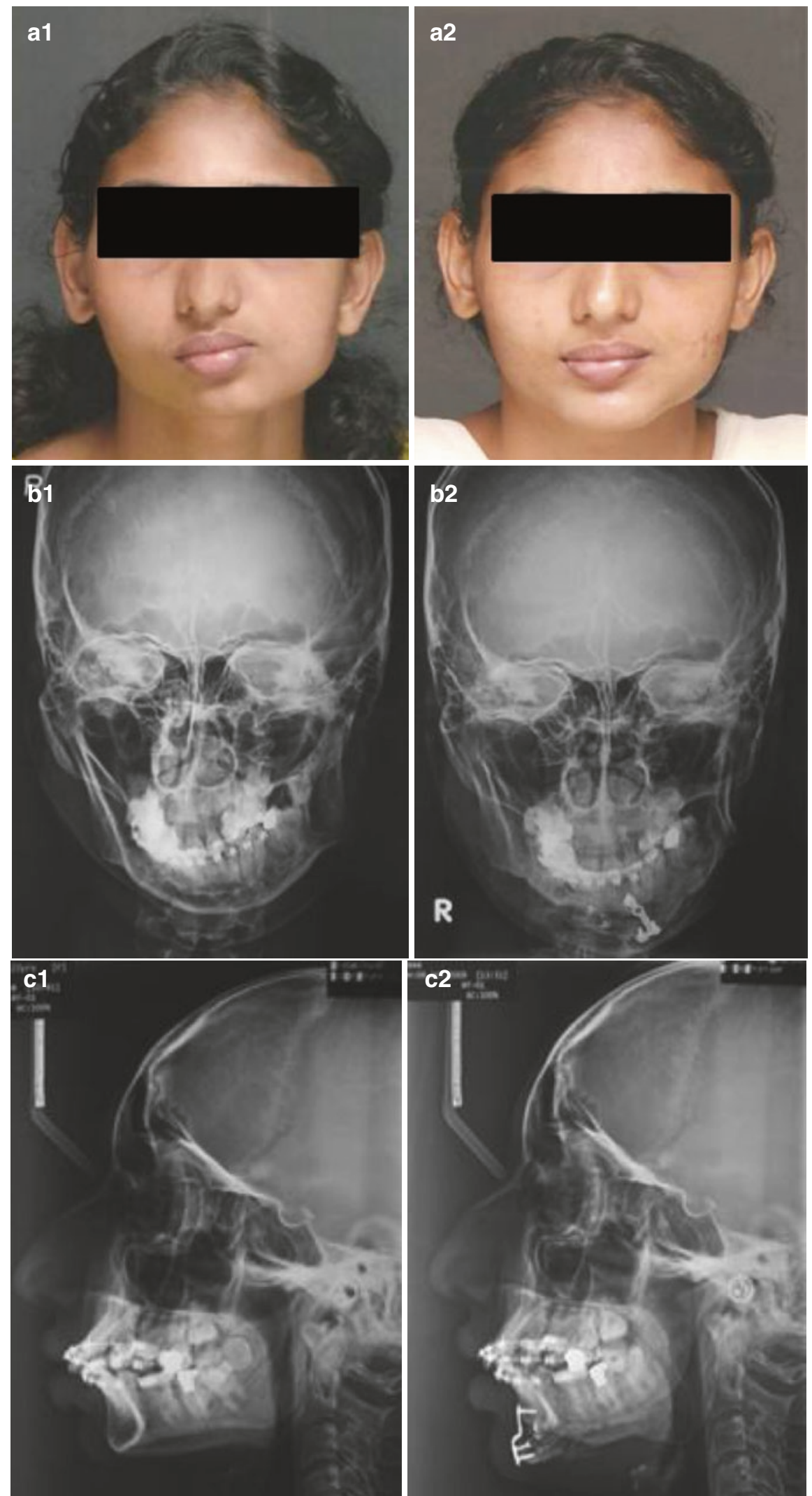

CAssociation of Oral and Maxillofacial Surgeons of India

Fig. 68.38 Mandibular asymmetry corrected by extended lateral sliding genioplasty. (a1) pre operative frontal view. (a2) post operative frontal view. $(\mathbf{b 1}, \mathbf{b 2})$ pre and post operative Frontal cephalogram. $(\mathbf{c 1 ,} \mathbf{c 2})$ pre and post operative lateral cephalogram 


\section{References}

1. Batra APS, Mahajan A, Gupta K. Marginal mandibular branch of the facial nerve: an anatomical study. Indian J Plast Surg. 2010;43(1):60-4.

2. Limberg A. Treatment of open bite by means of plastic oblique osteotomy of the ascending rami of the mandible. Dent Cosmos. 1925;67:1191-7.

3. Caldwell JB, Letterman GS. Vertical osteotomy in the mandibular rami for correction of prognathism. J Oral Surg. 1954;12:185-202.

4. Cosman B, Criilair G. Mandibular hyperplasia and the late development of glossopharyngeal airway obstruction. Plast Reconstr Surg. 1972;50:573-9.

5. Caldwell JB, Hayward JR, Lister RL. Correction of mandibular retrognathia by vertical L osteotomy: a new technique. J Oral Surg. 1968;26:259-64.

6. Obwegeser H, Trauner R. Zur Operationstechnik bei der progenie und anderen unterkieferanomalien. Dtsch Z Mund Kieferheilkd. 1955;23:H1-2.

7. Trauner R, Obwegeser H. Zur Operationstechnik bei der progenieund anderen unterkieferanomalien [The surgical correction of mandibular prognathism and retrognathia with consideration of genioplasty]. Dtsch Zahn Mund Kieferheilk. 1955;23(1):1-26.

8. DalPont G. Retromolar osteotomy for the correction of prognathism. J Oral Surg Anesth Hosp Dent Serv. 1961;19:42-7.

9. Hunsuck EE. Modified intraoral sagittal split technique for correction of mandibular prognathism. J Oral Surg. 1968;26:250-3.

10. Reitzik M, Barer PG, Wainwright WM, Lim B. The surgical treatment of skeletal anterior open-bite deformities with rigid internal fixation in the mandible. Am J Orthod Denthofac Orthop. 1990;97(1):52-7.

11. Hensel GC. The surgical correction of mandibular protection, retraction, and fractures of the ascending rami. Int J Orthodont Oral Surg. 1937;23:184.

12. Bell WH, Schendel SA. Biological basis for the modification of the sagittal ramus split operation. J Oral Surg. 1977;35:362-9.

13. Epker BN, Wolford LM, Fish LC. Mandibular deficiency syndrome: surgical considerations for mandibular advancement. Oral Surg. 1978;45:349-63.

14. Wolford LM. Influence of osteotomy design mandibular ramus sagittal split osteotomy. J Oral Maxillofac Surg. 2015;73(10):1994-2004.

15. Pietruski P, Majak M, Swiatek-Najwer E, Popek M, Szram D, Zuk M, Jaworowski J. Accuracy of experimental mandibular osteotomy using the image-guided sagittal saw. Int J Oral Maxillofac Surg. 2016;45:793-800.

16. Panula K, Finne K, Oikarinen K. Neurosensory deficits after bilateral sagittal split ramus osteotomy of the mandible-influences of soft tissue handling medial to the ascending ramus. Int J Oral Maxillofac Surg. 2004;33:543-8.

17. Tsuji Y, Muto T, Kawakami T, Takeda S. Computed tomographic analysis of the position and course of the mandibular canal: relevance to the sagittal split ramus osteotomy. Int J Oral Maxillofac Surg. 2005;34:243-6.

18. Promma L, Sakulsak N, Putiwat P, Amarttayakong P, Iamsaard S, Trakulsuk H, Hirunyakorn K, Suarbua S, Wattanaraeungchai Y. Cortical bone thickness of the mandibular canal and implications for bilateral sagittal split osteotomy: a cadaveric study Int. J Oral Maxillofac Surg. 2017;46:572-7.

19. Blair VP. Report of a case of double resection for the correction of protrusion of the mandible. Dent Cosmos. 1906;48:817-20.

20. Wolford LM, Cottrell DA. Diagnosis of macroglossia and indications for reduction glossectomy. Am J Orthod Dentofac Orthop. 1996;110:170-7.
21. Mommaerts MY. Endoscopically assisted sagittal split osteotomy for mandibular lengthening: technical note and initial experience. J Craniomaxillofac Surg. 2010;38:108-12.

22. Ellis E III, Gallo WJ. Relapse following mandibular advancement with dental plus skeletal maxillomandibular fixation. J Oral Maxillofac Surg. 1986;44:509-15.

23. Ellis E III, Reynolds S, Carlson DS. Stability of the mandible following advancement: a comparison of three post surgical fixation techniques. Am J Orthod Dentofac Orthop. 1988;94:38-49.

24. Schendel SA, Epkar BN. Result after mandibular advancement surgery: an analysis of 87 cases. J Oral Surg. 1980;38:265-81.

25. Rachmiel A, Aizenbud D, Pillar G, Srouji S, Peled M. Bilateral mandibular distraction for patients with compromised airway analyzed by three dimensional CT. Int J Oral Maxillofac Surg. 2005;34(1):9-18.

26. Laine P, Kontio R, Lindqvist C, Suuronen R. Are there any complications with bioabsorbable fixation devices? A 10 year review in orthognathic surgery. Int J Oral Maxillofac Surg. 2004;33:240-4.

27. Bell WH, Fonseca RJ, Kennedy JW III, Levy BM. Bone healing and revascularization after total maxillary osteotomy. J Oral Surg. 1975;33:253-60.

28. Bell WH, Levy BM. Revascularisation and bone healing after posterior maxillary osteotomy. J Oral Surg. 1971;29:313-20.

29. Bell WH. Revascularisation and bone healing after anterior maxillary osteotomy: a study using adult rhesus monkeys. J Oral Surg. 1969;27:249-55.

30. Stoelinga PJ, Borslap WA. The fixation of sagittal split osteotomies with mini plates the versatility of a technique. J Oral Maxillofac Surg. 2003;61:1471-6.

31. Foley WL, Beckman TW. In vitro comparison of screw versus plate fixation in the sagittal split ramus osteotomy. Int $\mathbf{J}$ Adult Orthodon Orthognath Surg. 1992;7:147-51.

32. Behrman SJ. Complications associated with orthognathic surgery. In: Irby WB, editor. Current advances in oral surgery. St Louis: CV Mosby; 1974. p. 109.

33. Storum KA, Bell WH. Hypo mobility after maxillary and mandibular osteotomies. J Oral Surg. 1984;57:7-12.

34. Aragon SB, VanSickels JE. Mandibular range of motion with rigid/no rigid fixation. Oral Surg. 1987;63:408-11.

35. Steenen SA, Becking AG. Bad splits in bilateral sagittal split osteotomy: systematic review of fracture patterns. Int J Oral Maxillofac Surg. 2016;45:887-97.

36. Aarabi M, Tabrizi R, Hekmat M, Shahidi S, Puzesh A. Relationship between mandibular anatomy and the occurrence of a bad split upon sagittal split osteotomy. J Oral Maxillofac Surg. 2014;72:2508-13.

37. Al Bishri A, Barghash Z, Rosenquist J, Sunzel B. Neurosensory disturbance after sagittal split and intra oral vertical ramus osteotomy: as reported in questionnaires and patients records. Int $\mathbf{J}$ Oral Maxillofac Surg. 2005;34:247-51.

38. Posnick JL, Qattan MM, Stepner NM. Alteration in focal sensibility in adolescents following sagittal split and chin osteotomies of the mandible. Plast Reconstr Surg. 1996;97:920-7.

39. Lake SL, McNeill RW, Little RM, West RA. Surgical mandibular advancement: a cephalometric analysis of treatment response. Am J Orthod. 1981;80:376-94.

40. Fariña R, Pintor F, Pérez J, Pantoja R, Berner D. Low condylectomy as the sole treatment for active condylar hyperplasia: facial, occlusal and skeletal changes. An observational study. Int J Oral Maxillofac Surg. 2015;44:217-25.

41. Lee SG, Kang YH, Byun JH, Kim UK, Kim JR, Park BW. Stability of unilateral sagittal split ramus osteotomy for correction of facial asymmetry: long-term case series and literature review. J Korean Assoc Oral Maxillofac Surg. 2015;41:156-64.

42. Mendez-Manjon I, Guijarro-Martınez R, Valls-Ontanon A, Hernandez-Alfaro F. Early changes in condylar position after 
mandibular advancement: a three-dimensional analysis. Int J Ora Maxillofac Surg. 2016;45:787-92.

43. Borstlap WA, Steolinga PJW, Hoppenreijs TJM, Van't Hof MA. Stabilization of sagittal split advancement osteotomies with mini plates: a prospective multi centre study with two year follow up part III - condylar remodeling and resorption. Int J Oral Maxillofac Surg. 2004;33:649-55.

44. Arnett GW, Milam SB, Gottesman L. Progressive mandibular retrusion-idiopathic condylar resorption part I. Am J Orthod Dentofac Orthop. 1996;110:8-15.

45. Alder ME, Deahl ST, Matteson SR, Van Sickel JE, Tiner BD, Rugh JD. Short term change of condylar position after sagittal split osteotomy for mandibular advancement. Orrl Surg Oral Med Oral Pathol Oral Radiol Endod. 1999;87:159-65.

46. Ueki K, Nakagawa K, Marukawa K, Takazakara D, Shimada M, Takatsuka S, Yamanoto E. Changes in condylar long axis and skeletal stability after bilateral sagittal split ramus osteotomy with poly-L-lactic acid or titanium plate fixation. Int J Oral Maxillofac Surg. 2005;34:627-34.

47. Mobarak KA, Espeland L, Krogstad O, Lyberg T. Mandibular advancement surgery in high-angle and low-angle class II patients: different long-term skeletal responses. Am J Orthod Dentofac Orthop. 2001;119:368-81.

48. Kojimoto H, Yasin N, Goto T, Matsudo S, Shimomura Y. Bone lengthening in rabbits by callus distraction. The role of periosteum and endosteum. J Bone Joint Surg Br. 1988;70:543-9.

49. Moose SM. Surgical correction of mandibular prognathism by intra oral subcondylar osteotomy. J Oral Surg. 1964;22:197-201.

50. Winstanley RP. Subcondylar osteotomy of the mandible and the intra oral approach. Br J Oral Surg. 1968;6:134-6.

51. Rokutanda S, Yamada S, Yanamoto S, Omori K, Fujimura Y, Morita Y, Rokutanda H, Kohara H, Fujishita A, Nakamura T, Yoshimi T, Yoshida N, Umeda M. Comparison of osseous healing after sagittal split ramus osteotomy and intraoral vertical ramus osteotomy. Int J Oral Maxillofac Surg. 2018;47(10):1316-21.

52. Al-Moraissi EA, Ellis E 3rd. Is there a difference in stability or neurosensoy func-tion between bilateral sagittal split ramus osteotomy and intraoral vertical ramus osteotomy for mandibular setback? J Oral Maxillofac Surg. 2015;73:1360-71.

53. Hall HD, Chase DC, Payor LG. Evaluation and refinement of the intraoral vertical subcondylar osteotomy. J Oral Surg. $1975 ; 33: 333-41$

54. Tornes K, Wisth PJ. Stability after vertical subcondylar ramus osteotomy for correction of mandibular prognathism. Int Oral Maxillofac Surg. 1988;17:242-8.

55. Nystrom E, Rosenquist J, Astrand P, Nordin T. Intraoral or extra oral approaches in oblique sliding osteotomy of the mandibular ramus. J Maxillofac Surg. 1984;12:277-82.

56. Reitzk M, Griffiths RR, Mirels H. Surgical anatomy of the ascending ramus of the mandible. Br J Oral Surg. 1976;14(2):150-5.

57. Goldstein A. Appraisal of results of surgical correction of class III malocclusions. Angle Orthod. 1974;17(3-4):59.

58. Komiri E, Aigase K, Sugisaki M, Tanabe H. Skeletal fixation versus skeletal relapse. Am J Orthod Dentofac Orthop. 1987;92(5):412-21.

59. Ghali GE, Sikes JW Jr. Intraoral vertical ramus osteotomy as the preferred treatment for mandibular prognathism. J Oral Maxillofac Surg. 2000;58:313e315.

60. González-García R. Endoscopically-assisted subcondylar and vertical ramus osteotomies for the treatment of symmetrical mandibular prognathism. J Craniomaxillofac Surg. 2012;40:393-5.

61. Poulton DR, Taylor RC, Ware WH. Cephalometric x-rays evaluation of the vertical osteotomy correction of mandibular prognathism. Oral Surg Oral Med Oral Pathol. 1963;16:807-20.
62. Ritzau M, Wenzel A, Williams S. Changing in condyle position after bilateral vertical ramus osteotomy with and without osteosynthesis. Am J Orthod Dentofac Orthop. 1989;96:507-13.

63. Sund G, Eckerdal O, Astrand P. Changes in the temporomandibular joint after oblique sliding osteotomy of the mandibular rami: a longitudinal radiological study. J Maxillofac Surg. 1983;11(2):87-91.

64. Hollender L, Ridell A. Radiography of the temporomandibular joint after oblique sliding osteotomy of the mandibular ramis. Scand J Dent Res. 1974;82:466-9.

65. Sund G, Eckerdal O, Astrand P. Skeletal remodeling in the temporomandibular joint after oblique sliding osteotomy of the mandibular rami. Int J Oral Maxillofac Surg. 1986;15(3):233-9.

66. Hullihen SP. Case of elongation of the under jaw and distortion of the face and neck, caused by a burn, successfully treated. Am J Dent Sci. 1849;9:157.

67. Hofer O. Operation der prognathie und Mikrogenie. Dtsch Zahn Mund Kieferheilk. 1942;9:121-32.

68. Boye T, Doyle P, McKeown F, Sandler J. Total subapical mandibular osteotomy to correct class 2 division 1, dento-facial deformity. J Craniomaxillofac Surg. 2011;40(3):238-42.

69. Bell WH, Gallagher DM. Versatility of genioplasty with broad pedicle. J Oral Maxillofac Surg. 1983;41:763-9.

70. Mercuri LG, Laskin DM. Avascular necrosis after anterior horizontal augmentation genioplasty. J Oral Surg. 1977;35:296-8.

71. Storum KA, Bell WH, Nagura H. Micro angiographic and histologic evaluation of revascularization and healing after genioplasty by osteotomy of the inferior border of the mandible. J Oral Maxillofac Surg. 1988;48:210-6.

72. Fitzpatrick BN. Reconstruction of the chin in cosmetic surgery (genioplasty). Oral Surg. 1975;39:522-35.

73. Cohen SR, Mardach OL, Kawawata HK. Chin disfigurement following removal of alloplastic chin implants. Plast Reconstr Surg. 1991;88:62.

74. Lopez PE, Guerrero CA, Mujica EV. Mandibular basal osteotomy: new designs and fixation techniques. J Oral Maxillofac Surg. 2011;69:786-97.

75. Troulis MJ, Kearns GJ, Perrott DH, Kaban LB. Extended genioplasty, long term cephalometric, nurpometric and sensory results. Int J Oral Maxillofac Surg. 2000;29:167-75.

76. Mani V, et al. Extended lateral sliding genioplasty for the correction of facial asymmetry. Asian J Oral Maxillofac Surg. 2004;16(2):84-90.

77. McCarthy JG, Schreiber JS, Karp NCH, Thorne CH, Grayson $\mathrm{BH}$. Lengthening of the human mandible by gradual distraction. Plast Reconstr Surg. 1992;89:1-10.

78. Raghoebar GM, Heydenrijk K, Vissink A. Vertical distraction of the severely resorbed mandible. The Groningen distraction device. Int J Oral Maxillofac Surg. 2001;59:728-33.

79. Suhr MAA, Kreatsch T. Technical considerations in distraction osteogenesis. Int J Oral Maxillofac Surg. 2004;33:89-94.

80. Hu J, Tang Z, Wang D, Buckley MJ. Changes in the inferior alveolar nerve after mandibular lengthening with different rates of distraction. J Oral Maxillofac Surg. 2001;108(5):1103-14.

81. Aida T, Yoshioka I, Tominaga K, Fukuda J. Effects of latency period in a rabbit mandibular distraction osteogenesis. Int $\mathrm{J}$ Oral Maxillofac Surg. 2003;32:54-62.

82. Tavakoli K, Walsh WR, Bonar F, Smart R, Wulf S, Poole M. The role of latency in mandibular osteo-distraction. J Craniomaxillofac Surg. 1998;26(4):209-19.

83. Troulis MJ, Glowacki J, Perrott DH, Kaban LB. The effects of latency and rate on distraction osteogenesis of the procine mandible. J Oral Maxillofac Surg. 2000;58(5):507-14.

84. Koudstaal MJ, Poort Poort LT, Vandel Wal KGH, Wolvers EB, Prahl Anderson B, Schulten AJM. Surgically assisted rapid max- 
illary expansion (SDRME) a review of the literature. Int J Oral Maxillofac Surg. 2005;34:709-14.

85. Karp NS, McCarthy JG, Schreiber JS, Sissions HA, Thorne CHM. Membranous bones lengthening: a serial histological study. Ann Plast Surg. 1992;29:2-7.

86. Al Ruhaimi KA. Comparison of different distraction rates in the mandible: an experimental investigation. Int J Oral Maxillofac Surg. 2001;30:220-7.

87. El-Hakin E, Azins AMA, El Hanson MFA, Maree SM. Preliminary investigation into the effects of electrical stimulation on mandibular distraction osteogenesis in goats. Int J Oral Maxillofac Surg. 2004;33:42-7.

88. Friedenberg ZB, Kohanin M. Effect of direct current on bone. Surg Gynecol Obstet. 1968;127:97-102.

89. Hagiwara T, Bell WH. Effect of electrical stimulation on mandibular distraction osteogenesis. J Craniomaxillofac Surg. 2000;28:12-9.

90. Hoffmeister B, Marks CH, Wolff KD. The floating bone concept in intraoral mandibular distraction. J Craniomaxillofac Surg. 1998;26:76-7.

91. McCarthy J, Hopper R, Hollier L, Peltomaki T, Katzen T, Grayson B. Molding of the degenerate in mandibular distraction-clinical experience. Plast Reconstr Surg. 2003;12:1239-46.

92. Peltonaki T, Greyson B, Venditelli B, Katzen T, McCarthy J. Moulding the generate to control open bite during mandibular distraction osteogenesis. Eur J Orthod. 2002;24:639-45.
93. Ow ATC, Cheung LK. Skeletal stability and complications of Bilateral Sagittal Split Osteotomies (BSSO) and Mandibular Distraction Osteogenesis (MDO): an evidence-based review. J Oral Maxillofac Surg. 2009;67:2344-53.

94. Baas EM, Bierenbroodspot F, de Lange J. Skeletal stability after bilateral sagittal split osteotomy or distraction osteogenesis of the mandible: a randomized clinical trial. Int J Oral Maxillofac Surg. 2015;44:615-20.

95. Sjolui S. Hypoplasia of the mandible as a cause of respiratory difficulties in the infant. Acta Paediatr Scand. 1950;39:255-6.

96. Keogh IJ, Troulis MJ, Monroy AA, Eavey RD, Kaban LB. Isolated microtia as a marker for unsuspected hemifacial microsomia. Arch Otolaryngol Head Neck Surg. 2007;13:997-1001.

97. Moore MH, Guzman-Stein G, Proudman TW, Abott AH, Netherway DJ, David DJ. Mandibular lengthening by distraction for airway obstruction in Treacher collins syndrome. J Craniofac Surg. 1994;5:22-5.

98. Morovic CG, Monasterio L. Distraction osteogenesis for obstructive apneas in patients with congenital craniofacial malformations. Plast Reconstr Surg. 2000;105:2324-30.

99. Perkins JA, Sie KCY, Miczuk K, Richardson MA. Airway management in children with cranio facial anomalies. Cleft Palate Craniofac J. 1997;34:135-40.

100. Pluijmers C, Caron JJM, Dunaway DJ, Wolvius EB, Koudstaal MJ, Posnick JC, Al-Quattan MM, Stepner NM. Alteration in facial sensibility in adolescents following sagittal split and chin osteotomies of the mandible. Plast Reconstr Surg. 1996;97:920-7.

Open Access This chapter is licensed under the terms of the Creative Commons Attribution 4.0 International License (http://creativecommons. org/licenses/by/4.0/), which permits use, sharing, adaptation, distribution and reproduction in any medium or format, as long as you give appropriate credit to the original author(s) and the source, provide a link to the Creative Commons license and indicate if changes were made.

The images or other third party material in this chapter are included in the chapter's Creative Commons license, unless indicated otherwise in a credit line to the material. If material is not included in the chapter's Creative Commons license and your intended use is not permitted by statutory regulation or exceeds the permitted use, you will need to obtain permission directly from the copyright holder. 